듬 SCHOOL of GRADUATE STUDIES

EAST TENNESSEE STATE UNIVERSITY
East Tennessee State University Digital Commons@ East Tennessee State University

\title{
Postcranial Morphology and the Locomotor Adaptations of Extant and Extinct Crocodylomorphs and Lepidosaurs
}

Laura Rooney

East Tennessee State University

Follow this and additional works at: https://dc.etsu.edu/etd

Part of the Paleobiology Commons, and the Paleontology Commons

\section{Recommended Citation}

Rooney, Laura, "Postcranial Morphology and the Locomotor Adaptations of Extant and Extinct Crocodylomorphs and Lepidosaurs" (2018). Electronic Theses and Dissertations. Paper 3418. https://dc.etsu.edu/etd/3418

This Thesis - Open Access is brought to you for free and open access by the Student Works at Digital Commons @ East Tennessee State University. It has been accepted for inclusion in Electronic Theses and Dissertations by an authorized administrator of Digital Commons@ East Tennessee State

University. For more information, please contact digilib@etsu.edu. 
Postcranial Morphology and the Locomotor Adaptations of Extant and Extinct Crocodylomorphs and Lepidosaurs

A thesis
presented to
the faculty of the Department of Geosciences
East Tennessee State University
of the requirements for the degree
Master of Science in Geosciences
Blaine Schubert
Chris Widga
by by
Laura Rooney 2018




\begin{abstract}
Postcranial Morphology and the Locomotor Adaptations of Extant and Extinct Crocodylomorphs and Lepidosaurs

by

Laura Rooney

I have collected a series of linear measurements of the postcranial skeletons of 43 extant crocodylian and lepidosaur taxa to determine if those engaging in similar locomotor behavior display similar morphology despite phylogenetic differences. Stepwise discriminant function analyses reveal reptile locomotor mode can be accurately predicted (over $80 \%$ correct) based on morphology. Semi-aquatic taxa are distinguished by a longer ischium relative to pubis length, a longer scapula relative to humerus length, and a broader acetabulum than terrestrial and arboreal taxa. Arboreal taxa display a more elongate, gracile humerus and a smaller acetabulum. This morphometric data can potentially be used to predict the locomotor behavior of a wide range of extinct reptile taxa. Within this study, Hyposaurus rogersii, Necrosuchus ionensis, Alligator sp. of the Gray Fossil Site, Crocodylus affinis, and Allognathosuchus mooki were examined and all were inferred to be semi-aquatic by the discriminant function analysis.
\end{abstract}




\section{TABLE OF CONTENTS}

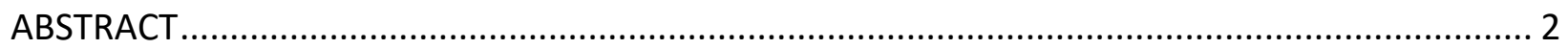

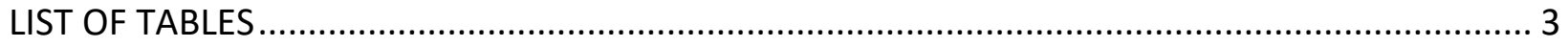

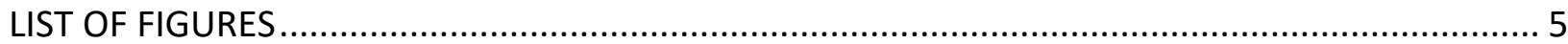

\section{Chapter}

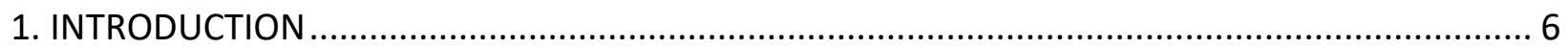

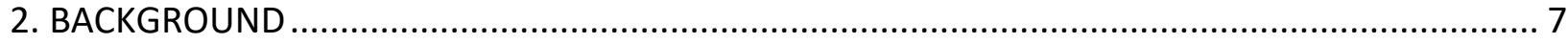

Evolution of Crocodylomorph and Lepidosaur Locomotion ............................................... 7

Locomotor Diversity of Crocodylomorphs and Lepidosaurs ........................................ 7

Past Studies Inferring Locomotion of Extinct Crocodylomorphs ...................................... 8

Skeletal Morphology Reflects Functional Performance ..................................................... 9

Quantitative Methods of Utilizing Postcrania to Infer Locomotion ...................................... 10

Past Studies Inferring Locomotion in Mammals ........................................................ 10

Linking Postcranial Morphology to Locomotor Behavior in Reptiles ................................ 11

Complications When Examining Reptiles vs. Mammals .............................................. 11

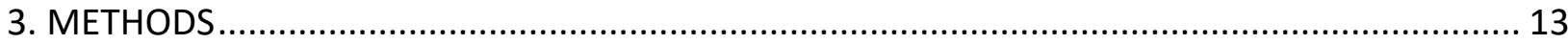

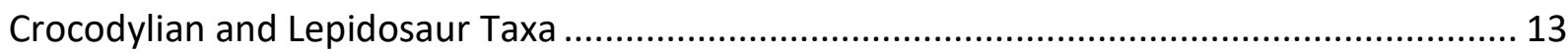

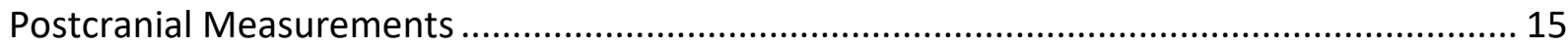

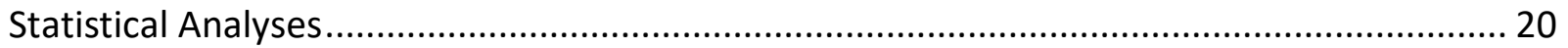

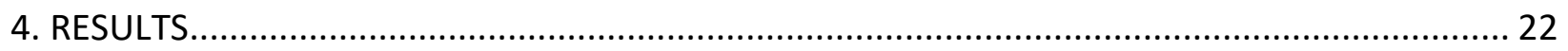

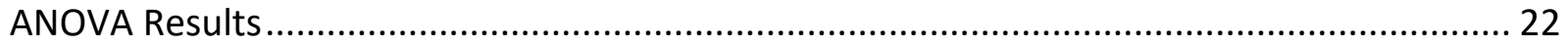

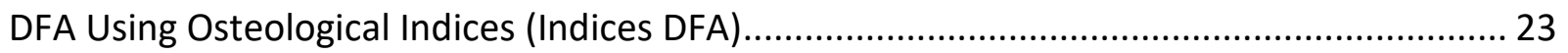

DFA Using Geometric Mean Transformed Variables (GM DFA) ......................................... 25

Inferred Locomotor Modes of Extant Lepidosaur and Crocodylian Taxa.............................. 27

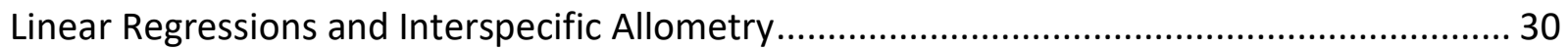

Inferred Locomotor Modes of Extinct Crocodylians....................................................... 37

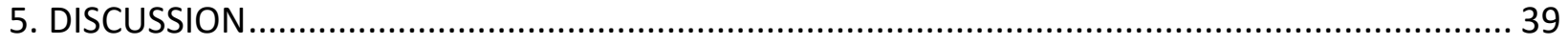

Correlation of Postcranial Morphology with Locomotor Mode in Extant Crocodylians and

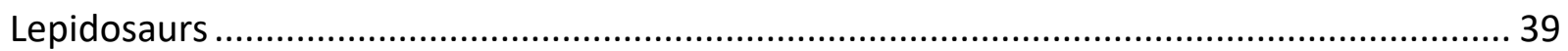

Assessment of Convergence in Lepidosaurs and Crocodylians ......................................... 42

Applications for Analyzing Locomotor Diversity of Extinct Reptiles..................................... 48

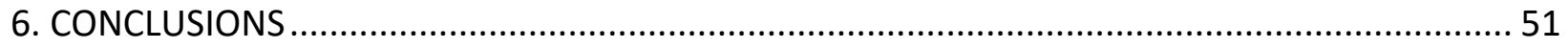

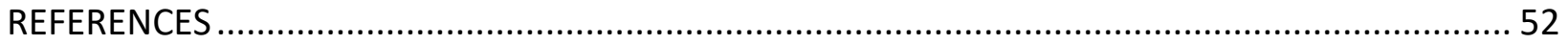

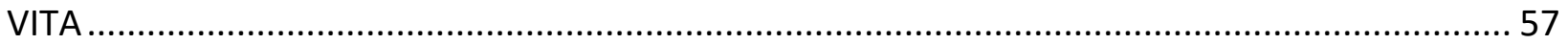




\section{LIST OF TABLES}

Table Page

1. List of extant species included in analysis......................................................................... 13

2. Locomotor categories used in the analyses and their definitions................................... 15

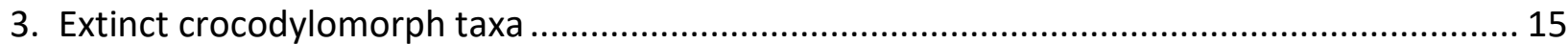

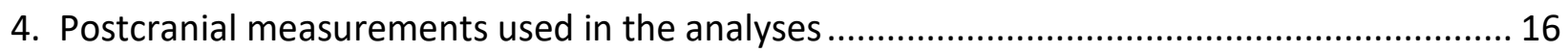

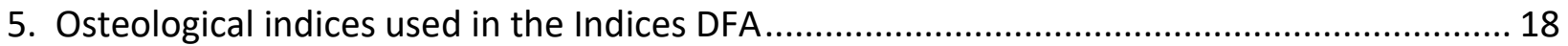

6. Mean values and standard deviations of indices for each locomotor group ....................... 22

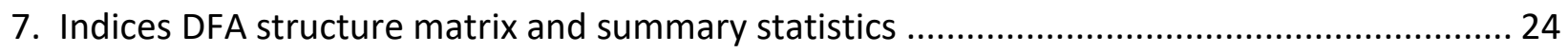

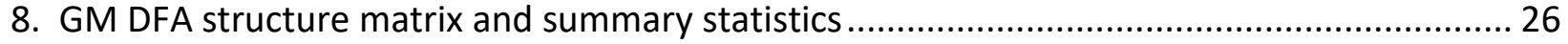

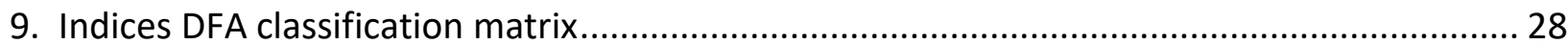

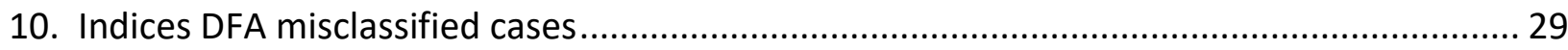

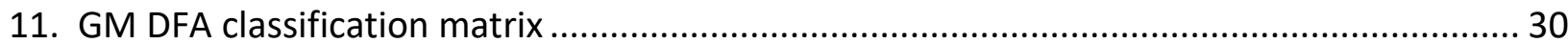

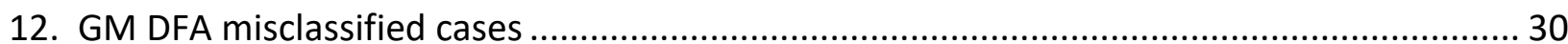

13. Z-scores displaying the influence of allometry on variables identified by the DFAs............ 33

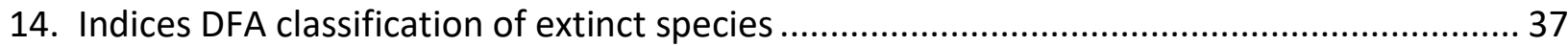

15. Z-scores displaying the influence of allometry on different locomotor groups.................. 46 


\section{LIST OF FIGURES}

Figure Page

1. Measurements of the axial and appendicular skeleton used in this study ......................... 17

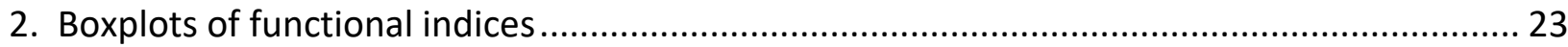

3. Plot of DF1 and DF2 scores for extant reptile taxa analyzed in the Indices DFA................... 25

4. Plot of DF1 and DF2 scores for extant reptile taxa analyzed in the GM DFA ...................... 27

5. Plots of selected functional indices and GM transformed variables versus the log geometric

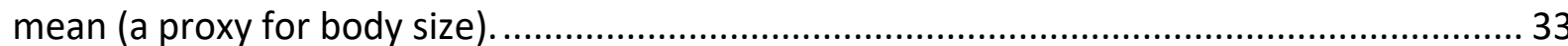

6. Log/log plots of variable components that displayed significance within the Indices DFA and

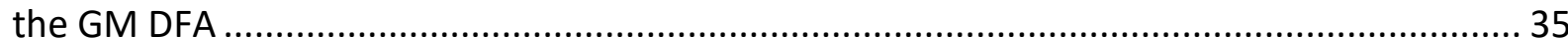

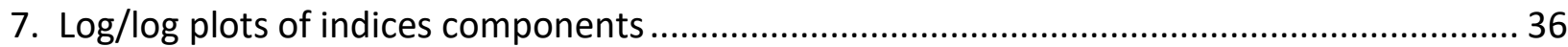

8. Plot of DF1 and DF2 discriminant scores for the Indices DFA including extinct taxa ............. 38

9. Plots of DF1 and DF2 scores for extant reptile taxa analyzed in the Indices DFA .................. 43

10. Plot of geometric mean versus DF1 scores of the Indices DFA ....................................... 45

11. Composite phylogenetic tree of reptile species included within the study ....................... 46 


\section{CHAPTER 1}

\section{INTRODUCTION}

Studies have shown that the morphology of the postcranial skeleton can be correlated with the known locomotor behavior of extant taxa (e.g. Losos 1990; Wainwright 2007; Samuels and Van Valkenburgh 2008; Samuels et al. 2013; Chen and Wilson 2015). These data can then be used to infer the locomotor modes of extinct taxa based on their morphological similarity to extant groups. Such studies have been conducted on many groups of mammals, however studies on reptiles are less common. Through linear morphometric analysis of extant crocodylian and lepidosaur postcrania, we can determine the presence or absence of convergent morphology in reptile taxa utilizing similar locomotor modes. 


\section{CHAPTER 2}

\section{BACKGROUND}

\section{Evolution of Crocodylomorph and Lepidosaur Locomotion}

\section{Locomotor Diversity of Crocodylomorphs and Lepidosaurs}

Crocodylomorphs are a group of archosaurs that includes extant crocodylians and their extinct relatives. There are 23 known species of extant crocodylians which are placed in three families; Crocodylidae (true crocodiles), Alligatoridae (alligators and caimans), and Gavialidae (gharial and false gharial). All modern crocodylians are semi-aquatic and spend a majority of their life in the water, however they construct terrestrial nests and regularly come ashore to bask. Gavialis is considered to be the most aquatic of the extant taxa, while caimans occupy the broadest range of habitats (Vitt and Caldwell 2014). The Order Crocodylia has remained largely unchanged ecomorphologically since its origins approximately 83.5 million years ago with all members engaging in similarly semi-aquatic behavior. Early members of the broader superorder, Crocodylomorpha, originated in the Late Triassic and are considered to have occupied a much wider range of niches, including some fully terrestrial taxa (e.g. Postosuchus, Prestosuchus, Poposaurus) and fully aquatic taxa (e.g. Metriorhynchus) (Chatterjee 1985; Grange 1998; Gauthier et al. 2011; Irmis et al. 2013; Liparini and Schultz 2014).

Lepidosauria, is a superorder of reptiles which includes lizards, snakes, amphisbaenians, and tuataras. With over 10,000 extant species, over 6,000 of which are lizards, Lepidosauria is highly diverse and includes many arboreal/scansorial, terrestrial, semi-aquatic, semi-fossorial, fossorial, and saltatorial species. Examples of these taxa include the arboreal chameleon Bradypodion, terrestrial agamid Trapelus, semi-aquatic varanid Varanus salvator, semi-fossorial 
skink Liopholis, and saltatorial-fossorial lacertid Acanthodactylus cantoris (Vitt and Caldwell 2014). Similar to crocodylomorphs, the earliest lizards are thought to have originated during the Late Triassic. Although the diversity of locomotor behavior of crocodylomorphs has greatly decreased since the Mesozoic, lepidosaurs have retained a high distribution of locomotor modes and thus represent potential modern analogs for extinct crocodylomorphs and other amniotes which appear to have engaged in higher degrees of terrestrial behavior.

Several extant families of lepidosaurs display a wide array of locomotor specializations among their taxa. The family Iguanidae, for example, contains arboreal species (e.g. Iguana iguana), terrestrial species (e.g. Cyclura cornuta), and a semi-aquatic species (Amblyrhyncus cristatus) (Vitt and Caldwell 2014). A similar distribution of locomotor behaviors is seen among agamids with arboreal representatives (e.g. Japalura mitsukurii), terrestrial species (e.g. Trapelus sanguinolenta), and the semi-aquatic Hydrosaurus pustulatus and Physignathus cocincinus (Vitt and Caldwell 2014). Other lepidosaur families also display species with semiaquatic adaptations, like the Asian water monitor (Varanus salvator) of the family Varanidae, and the northern caiman lizard (Dracaena guianensis) of the family Teiidae. Morphometric measurements and comparisons of postcrania for representatives of these locomotor groups within Lepidosauria may reveal that morphology reflects locomotor behavior in reptiles, regardless of evolutionary relationships, and indicate convergence or parallel evolution of locomotor adaptations among clades.

\section{Past Studies Inferring Locomotion of Extinct Crocodylomorphs}

The locomotor behavior of crocodylomorphs has often been interpreted from crania based on the orientation of the nasals and orbitals, as well as from qualitative analyses of the 
postcrania. It is only in recent years that researchers have begun more thorough examinations of crocodylomorph postcrania to interpret their adaptations for aquatic and terrestrial locomotion (Hua and Buffrenil 1996; Hua 2003; Stein et al. 2017). For example, Schachner (2011) reconstructed the muscles of the pelvis and hindlimbs of the extinct crocodylomorph Poposaurus gracilis based on the bone and muscle structure found in modern alligators and lepidosaurs. Molnar et al. (2015) examined the lumbar and thoracic vertebrae of modern crocodiles and several extinct crocodylomorphs to determine if variations in the range of motion and joint stiffness of the vertebrae could explain their varying locomotor capabilities. Morphological studies such as these are invaluable to understanding the development of locomotor capabilities through the course of crocodylian evolution. Detailed quantitative studies of extant reptiles can reveal aspects of their morphology that distinguish species with differing locomotor ecology, often based on limited material. The fossil material available for many species of extinct crocodylomorphs is limited, thus it is vital to determine reliable methods of inferring locomotion from whatever skeletal material is present.

\section{Skeletal Morphology Reflects Functional Performance}

Studies of a wide range of organisms have demonstrated the utility of skeletal morphology in reflecting functional capabilities. Often, patterns have demonstrated that organisms engaging in similar behaviors display similar morphologies (Wainwright 2007; Losos 2011). Cranial, postcranial, and dental morphologies have been used as signals for dietary preferences, locomotor capabilities, and even the evolutionary history of extant taxa ( $\mathrm{O}^{\prime}$ Keefe and Carrano 2005; Stayton 2006; Wainwright 2007; Samuels and Van Valkenburgh 2008; Polly et al. 2011; Da Silva et al. 2018). This ability is of great value to paleontologists as, frequently, skeletons are the 
only portion of organisms that become fossilized. Extant taxa provide us with the opportunity to examine the morphologies associated with particular ecologies, then quantitatively infer the habits of extinct groups based on their morphology.

\section{Quantitative Methods of Utilizing Postcrania to Infer Locomotion}

\section{$\underline{\text { Past Studies Inferring Locomotion in Mammals }}$}

Researchers of mammalian locomotion have repeatedly displayed the utility of using linear morphological measurements of mammal postcrania to create osteological indices that can be used to identify locomotor modes (e.g. Van Valkenburgh 1987; Samuels and Van Valkenburgh 2008; Rose et al. 2014; Chen and Wilson 2015; Tulli et al. 2015). Based on the methodology applied to carnivore locomotion in Van Valkenburgh 1987, Samuels and Van Valkenburg (2008) took measurements of the limbs of a diverse sample of extant rodent taxa and found their locomotor mode closely reflected their postcranial morphology, despite belonging to evolutionarily distinct groups. Application to extinct rodent species allowed quantitative inference of their locomotor habits. Samuels et al. (2013) utilized the same methodology to interpret locomotor behavior in extant and extinct carnivorans. Both studies measured proportions of the limb bones and calculated a series of osteological indices, which were analyzed using analysis of variance (ANOVA) and stepwise discriminant function analysis (DFA). Chen and Wilson (2015) then displayed that these analyses can be applied on an even broader scale by collecting postcranial data from over 100 small-bodied mammal taxa that spanned 15 orders. With the use of ANOVA and canonical variate analyses (CVA), these researchers once again found that postcranial morphology reflects locomotion and that this 
methodology could be applied to infer the locomotor modes of several Mesozoic mammal taxa. Each of these studies indicate that mammal taxa engaging in similar locomotor behavior tend to converge on particular morphologies, regardless of evolutionary relationships.

\section{Linking Postcranial Morphology to Locomotor Behavior in Reptiles}

Given the diversity of ecology and morphology of extant reptiles, it would be expected that form would reflect function, as similar patterns were observed in studies of mammals. To date, there have been a number of quantitative ecomorphological studies of reptiles that have shown just that (Pianka 1969; Pounds et al. 1983; Garland and Losos 1994). Examinations of postcranial proportions have been applied when interpreting the locomotor systems and ecomorphologies of groups of reptiles such as plesiosaurs (O'Keefe and Carrano 2005) and Anolis lizards (Losos 1990); thus, there is potential for applying a similar methodology to other groups of reptiles. In the past, the skull and lower jaw morphology of extant squamates has been used to demonstrate convergence among species with similar diets (Stayton 2006; Klaczko 2016). As crania of reptiles have indicated morphological and functional convergence based on diet, it is possible that reptilian postcrania exhibit similar convergence based on locomotor mode. A wide variety of locomotor specialists are seen in multiple families of extant reptiles, among both crocodylians and lepidosaurs, thus these groups provide the opportunity for examining potential convergent or parallel evolution within reptile clades.

\section{Complications When Examining Reptiles vs. Mammals}

While several of the simple linear measurements that have been collected from mammals for locomotor studies can easily be applied to reptile taxa, such as lengths of the limb bones and components of the pectoral and pelvic girdles, there are multiple anatomical 
distinctions between the two classes that must be noted. For example, mammalian locomotor studies frequently measure the length of the olecranon process of the ulna (ex. Van Valkenburgh 1987; Samuels and Van Valkenburgh 2008; Chen and Wilson 2015), but this feature is not present in reptilian taxa (Romer 1997). In addition, the pectoral girdles of these groups are quite different in that reptiles possess a coracoid which forms the ventral portion of the shoulder girdle (Romer 1997). This feature is absent in all placental mammals, thus new measurements must be determined to accurately represent this feature.

Consideration must also be taken when choosing which postcranial components are to be the primary focus of the study. Mammalian locomotor studies have primarily conducted analyses on the appendicular skeleton as locomotion of most mammals is primarily driven by the limbs, and thus the limbs and girdles display the primary muscle attachment sites for locomotion. However, in reptiles the axial skeleton frequently plays a much larger role in locomotor capabilities, especially for semi-aquatic taxa such as crocodylians. Semi-aquatic crocodylians and lepidosaurs rarely utilize their limbs for aquatic behavior, but rather propel themselves through the water by mediolateral undulation of their paddle-like tails (Hildebrand 1985; Grenard 1991). Therefore, when conducting an ecomorphological analysis of reptilian taxa, the inclusion of measurements of the axial skeleton, particularly the caudal vertebrae, may be key to examining and interpreting locomotor behavior. 


\section{CHAPTER 3}

\section{METHODS}

\section{Crocodylian and Lepidosaur Taxa}

A total of 57 extant crocodylian and lepidosaur specimens from ten families (37 species)

are represented within this study (Table 1). Families include Crocodylidae, Alligatoridae,

Agamidae, Iguanidae, Varanidae, Teiidae, Dactyloidae, Hoplocercidae, Cordylidae, and

Helodermatidae. The majority of species are represented by one specimen, however additional

specimens were measured when available to better portray the morphology of the species.

Table 1: List of extant species included in analysis

\begin{tabular}{lllll}
\hline Species \# & Family & Species name & N & Locomotor group \\
\hline 1 & Agamidae & Hydrosaurus pustulatus & 2 & Semi-aquatic \\
2 & Agamidae & Trapelus sanguinolentus & 1 & Terrestrial \\
3 & Agamidae & Japalura mitsukurii & 1 & Arboreal \\
4 & Agamidae & Stellagama stellio & 1 & Terrestrial \\
5 & Agamidae & Phrynocephalus przewalski & 1 & Terrestrial \\
6 & Cordylidae & Cordylus giganteus & 1 & Terrestrial \\
7 & Agamidae & Bronchocela cristatella & 1 & Arboreal \\
8 & Agamidae & Physignathus sp. & 4 & Semi-aquatic \\
9 & Agamidae & Uromastyx sp. & 3 & Terrestrial \\
10 & Alligatoridae & Paleosuchus trigonatus & 2 & Semi-aquatic \\
11 & Alligatoridae & Alligator mississippiensis & 3 & Semi-aquatic \\
12 & Alligatoridae & Alligator sinensis $*$ & 1 & Semi-aquatic \\
13 & Alligatoridae & Melanosuchus niger & 1 & Semi-aquatic \\
14 & Alligatoridae & Caiman crocodilus & 1 & Semi-aquatic \\
15 & Crocodylidae & Crocodylus acutus & 1 & Semi-aquatic \\
16 & Crocodylidae & Crocodylus moreletti & 1 & Semi-aquatic \\
17 & Crocodylidae & Crocodylus mindorensis & 1 & Semi-aquatic \\
18 & Crocodylidae & Gavialis gangeticus & 1 & Semi-aquatic \\
19 & Crocodylidae & Tomistoma schlegelli & 1 & Semi-aquatic \\
20 & Dactyloidae & Anolis equestris & 1 & Arboreal \\
21 & Helodermatidae & Heloderma suspectum & 1 & Terrestrial \\
22 & Hoplocercidae & Enyalioides oshaughnessyi & 3 & Arboreal \\
23 & Iguanidae & Amblyrhynchus cristatus & 2 & Semi-aquatic \\
24 & Iguanidae & Cyclura cornuta & 1 & Terrestrial \\
25 & Iguanidae & Cyclura cychlura & 1 & Terrestrial \\
26 & Iguanidae & Iguana iguana & 1 & Arboreal \\
27 & Iguanidae & Dipsosaurus dorsalis & 1 & Terrestrial
\end{tabular}




$\begin{array}{lllll}28 & \text { Iguanidae } & \text { Callisaurus draconoides } & 1 & \text { Terrestrial } \\ 29 & \text { Iguanidae } & \text { Conolophus subcristatus } & 1 & \text { Terrestrial } \\ 30 & \text { Iguanidae } & \text { Ctenosaura acanthura } & 1 & \text { Arboreal } \\ 31 & \text { Iguanidae } & \text { Ctenosaura similis } & 2 & \text { Terrestrial } \\ 32 & \text { Iguanidae } & \text { Ctenosaura hemilopha } & 1 & \text { Terrestrial } \\ 33 & \text { Teiidae } & \text { Dracaena guianensis } & 1 & \text { Semi-aquatic } \\ 34 & \text { Teiidae } & \text { Tupinambus merianae } & 1 & \text { Terrestrial } \\ 35 & \text { Teiidae } & \text { Ameiva ameiva } & 1 & \text { Terrestrial } \\ 36 & \text { Iguanidae } & \text { Sauromalus ater } & 1 & \text { Terrestrial } \\ 37 & \text { Varanidae } & \text { Varanus bengalensis } & 1 & \text { Terrestrial } \\ 38 & \text { Varanidae } & \text { Varanus griseus } & 1 & \text { Terrestrial } \\ 39 & \text { Varanidae } & \text { Varanus gouldi } & 1 & \text { Terrestrial } \\ 40 & \text { Varanidae } & \text { Varanus salvator } & 2 & \text { Semi-aquatic } \\ 41 & \text { Varanidae } & \text { Varanus komodoensis } & 1 & \text { Terrestrial } \\ 42 & \text { Varanidae } & \text { Varanus exanthematicus } & 1 & \text { Terrestrial } \\ 43 & \text { Varanidae } & \text { Varanus beccarii } & 1 & \text { Arboreal }\end{array}$

Captive specimens are indicated by *.

Each species studied was categorized into one of three locomotor modes (Table 2)

based on published descriptions of their behavior (Vitt and Caldwell 2014, IUCN). Some taxa are characterized by multiple behaviors and categorizations were made based on the predominance of evidence. Thus, these categories are a simplification of a complex continuum of locomotor behaviors. Lepidosaur families that include members with a variety of locomotor modes were preferentially selected to allow comparisons of closely related taxa with disparate ecology. Specimens were also chosen based on completeness of available postcrania, and the sample includes both male and female individuals. Most of the specimens examined are wildcaught adults; however, occasional juveniles have been used where adult specimens were unavailable. Data for extant specimens were gathered from the reptile collections of the Smithsonian Institution National Museum of Natural History (NMNH), Washington, D.C.; the East Tennessee State University Museum of Natural History (ETMNH), Gray, TN; and the East Tennessee State University modern osteology collections (ETMNH), Johnson City, TN. 
Table 2: Locomotor categories used in the analyses and their definitions

\begin{tabular}{ll}
\hline Locomotor Mode & Definition \\
\hline Terrestrial (T) & Primarily displays quadrupedal behavior on land, potentially with slight \\
& burrowing behavior. Rarely if ever swims or climbs. \\
Semi-aquatic (Sa) & Regularly swims for dispersal, escape, or foraging. \\
Arboreal (A) & $\begin{array}{l}\text { Displays frequent climbing behavior for escape, shelter, or foraging. } \\
\text { Includes scansorial species. }\end{array}$
\end{tabular}

Table 1 includes a complete list of the included extant species and their designated locomotor modes. Species were assigned to locomotor groups based on descriptions of their behavior found in Vitt and Caldwell, 2014 and IUCN.org.

Nineteen specimens of extinct crocodylomorph taxa (Table 3) spanning ten families were included in the analysis as well to infer their primary locomotor behaviors. Fossil specimens were examined from the vertebrate paleontology collections of the American Museum of Natural History (AMNH), New York, NY and the New Jersey State Museum (NJSM), Trenton, NJ. Table 3: Extinct crocodylomorph taxa

\begin{tabular}{lll}
\hline Family & Species name & N \\
\hline Alligatoridae & Alligator sp. (Gray Fossil Site) & 4 \\
Alligatoridae & Allognathosuchus mooki & 1 \\
Alligatoridae & Necrosuchus ionensis & 1 \\
Crocodylidae & Bottasaurus harleni & 1 \\
Crocodylidae & Crocodylus affinis & 1 \\
Crocodylidae & Holops obscurus & 1 \\
Dyrosauridae & Hyposaurus rogersii & 1 \\
Gavialoidea & Thoracosaurus sp. & 3 \\
Goniopholidae & Goniopholis sp. & 1 \\
Stem crocodylian & Hesperosuchus agilis & 1 \\
Pholidosauridae & Teleorhinus robustus & 1 \\
Prestosuchidae & Prestosuchus chiniquensis & 1 \\
Pristichampsidae & Pristichampsus vorax & 1 \\
Rauisuchidae & Protosuchus sp. & 1
\end{tabular}

\section{Postcranial Measurements}

I used digital calipers to measure a total of 40 linear measurements of the postcranial skeleton (Table 4) using digital calipers to measure to the nearest $0.01 \mathrm{~mm}$. Measurements primarily consisted of total lengths of limb bones as well as proximal, distal, and midshaft 
widths of these elements. The bones of the pectoral and pelvic girdles were also measured, along with three caudal vertebrae from each specimen, acting as representatives for three designated segments of the tail (anterior, midway, and posterior). Due to the broad variation in tail lengths and caudal vertebra number across taxa, the caudal vertebrae selected to represent the midway and posterior sections were chosen based on the overall length of the individual's tail.

Table 4: Postcranial measurements used in the analyses

\begin{tabular}{ll}
\hline Measurement & Abbreviation \\
\hline Humerus proximal breadth & $\mathrm{HPB}$ \\
Humerus proximal width & $\mathrm{HPW}$ \\
Humerus distal breadth & $\mathrm{HDB}$ \\
Humerus distal width & $\mathrm{HDW}$ \\
Humerus length & $\mathrm{HL}$ \\
Humerus mid-shaft diameter & $\mathrm{HMSD}$ \\
Deltopectoral ridge length & $\mathrm{DPRL}$ \\
Deltopectoral ridge height & $\mathrm{DPRH}$ \\
Radius length & $\mathrm{RL}$ \\
Ulna length & $\mathrm{UL}$ \\
Femur length & $\mathrm{FL}$ \\
Femoral mid-shaft diameter & $\mathrm{FMSD}$ \\
Femur proximal length & $\mathrm{FPL}$ \\
Femur proximal width & $\mathrm{FPW}$ \\
Femur distal length & $\mathrm{FDL}$ \\
Femur distal width & $\mathrm{FDW}$ \\
Linea aspera & $\mathrm{LA}$ \\
Tibia length & $\mathrm{TL}$ \\
Tibia mid-shaft diameter & $\mathrm{TMSD}$ \\
Fibula length & $\mathrm{FibL}$ \\
Fibula mid-shaft diameter & $\mathrm{FibMSD}$ \\
Centrum height of anterior caudal vertebra & $\mathrm{CH}-\mathrm{ACV}$ \\
Centrum length of anterior caudal vertebra & $\mathrm{CL}-\mathrm{ACV}$ \\
Transverse processes of anterior caudal vertebra & $\mathrm{TP}-\mathrm{ACV}$ \\
Neural spine of anterior caudal vertebra & $\mathrm{NS}-\mathrm{ACV}$ \\
Centrum height of midway caudal vertebra & $\mathrm{CH}-\mathrm{MCV}$ \\
Neural spine of midway caudal vertebra & $\mathrm{NS}-\mathrm{MCV}$ \\
Hemal spine height & $\mathrm{HSH}$ \\
Sacrum length & $\mathrm{SaCL}$ \\
Acetabulum diameter & $\mathrm{AcetD}$ \\
Ilium length & $\mathrm{IIL}$ \\
Ilium width & $\mathrm{IIW}$ \\
&
\end{tabular}


Ischium length

Ischium width

Pubis length

Pubis width

Scapula length

Scapula width

Coracoid length

Coracoid width
IschL

IschW

Publ

PubW

ScapL

ScapW

CorL

CorW

Measurements are illustrated in Figure 1.

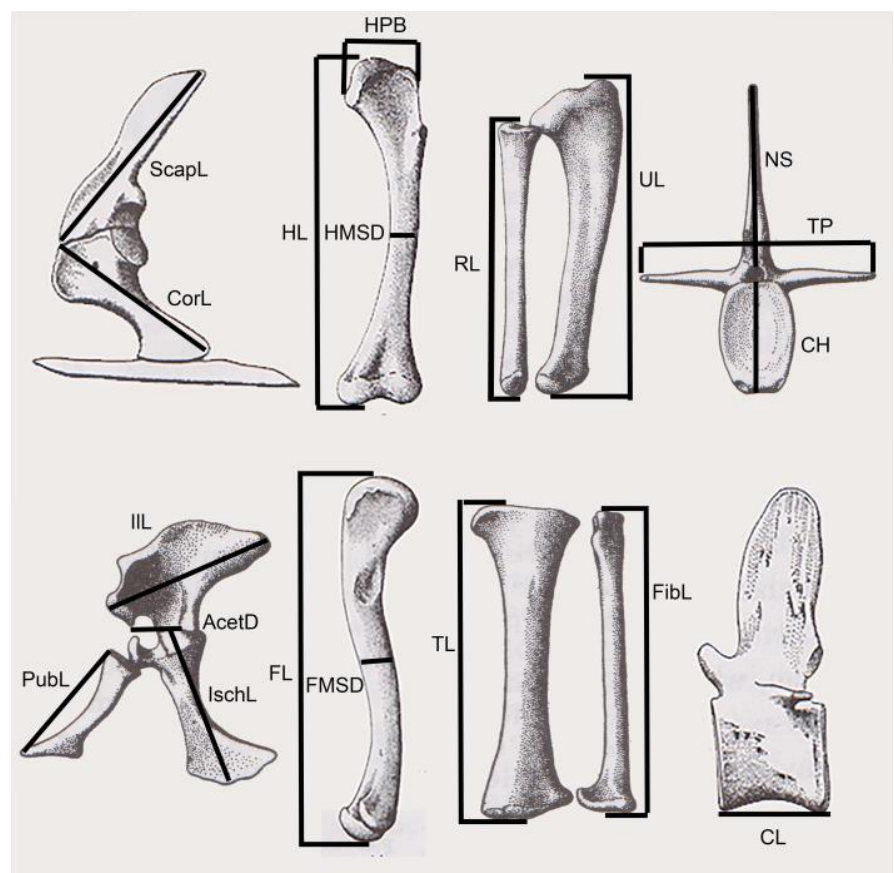

Figure 1: Measurements of the axial and appendicular skeleton used in this study Images modified from Romer 1997.

Since this study covers a wide distribution of taxa across Reptilia, significant size differences between specimens are present. Linear measurements were used to calculate a set of 22 osteological indices (Table 5), which reflect relative proportions and help to account for variations in size between species. These indices allow us to visualize overall limb and tail proportions and interpret variations in velocity ratio and mechanical advantage along these appendages that can reflect particular locomotor adaptations. 
Table 5: Osteological indices used in the Indices DFA

\begin{tabular}{|c|c|}
\hline Index & Definition \\
\hline Proximal forelimb index (PFI) & $\begin{array}{l}\text { Scapula length divided by humerus length (ScapL/HL). } \\
\text { Indicates speed of movement via relative proportions of } \\
\text { components of the proximal forelimb. }\end{array}$ \\
\hline Humeral robustness index (HRI) & $\begin{array}{l}\text { Mid-shaft diameter of humerus divided by humerus } \\
\text { length }(\mathrm{MSDH} / \mathrm{HL}) \text {. Indicates humeral robustness and } \\
\text { resistance to bending and shearing. }\end{array}$ \\
\hline Humeral proximal robustness index (HPRI) & $\begin{array}{l}\text { Humerus proximal breadth divided by humerus length. } \\
\text { Indicates robustness and strength of proximal humerus. }\end{array}$ \\
\hline Humeral distal robustness index (HDRI) & $\begin{array}{l}\text { Humerus distal breadth divided by humerus length. } \\
\text { Indicates robustness and strength of distal humerus. }\end{array}$ \\
\hline Shoulder moment index (SMI) & $\begin{array}{l}\text { Deltopectoral crest length divided by humerus length } \\
\text { (DPCL/HL). Displays mechanical advantage of deltoid and } \\
\text { pectoral muscles at the shoulder joint. }\end{array}$ \\
\hline Brachial index (BI) & $\begin{array}{l}\text { Ulna length divided by humerus length (UL/HL). Indicates } \\
\text { relative proportions of proximal and distal elements of } \\
\text { the forelimb. }\end{array}$ \\
\hline Brachial index 2 (BI2) & $\begin{array}{l}\text { Radius length divided by humerus length (RL/HL). } \\
\text { Indicates relative proportions of proximal and distal } \\
\text { elements of the forelimb. }\end{array}$ \\
\hline Middle forelimb index (MFI) & $\begin{array}{l}\text { Radius length divided by ulna length (RL/UL). Indicates } \\
\text { relative size of musculature controlling extension of } \\
\text { distal forelimb. }\end{array}$ \\
\hline Crural index $(\mathrm{Cl})$ & $\begin{array}{l}\text { Tibia length divided by femur length (TL/FL). Indicates } \\
\text { relative proportions of proximal and distal elements of } \\
\text { the hindlimb. }\end{array}$ \\
\hline Femoral robustness index (FRI) & $\begin{array}{l}\text { Midshaft diameter of femur divided by femur length } \\
\text { (MSDF/FL). Indicates robustness of femur and its } \\
\text { resistance to bending and shearing. }\end{array}$ \\
\hline Intermembral index (IMI) & $\begin{array}{l}\text { Humerus length and radius length divided by femur } \\
\text { length and tibia length }[(H L+R L) /(F L+T L)] \text {. Indicates } \\
\text { relative lengths of forelimb and hindlimb. }\end{array}$ \\
\hline Tibial robustness index (TRI) & $\begin{array}{l}\text { Midshaft diameter of tibia divided by tibia length } \\
\text { (MSDT/TL). Indicates resistance of tibia to bending and } \\
\text { shearing. }\end{array}$ \\
\hline Body length index (BLI) & $\begin{array}{l}\text { Total length of trunk vertebrae (thoracic and lumbar if } \\
\text { applicable) divided by total length of caudal vertebrae. } \\
\text { Indicates relative proportion of trunk length to tail } \\
\text { length. }\end{array}$ \\
\hline $\begin{array}{l}\text { Neural spine index for anterior } \\
\text { caudal vertebra (NSI-ACV) }\end{array}$ & $\begin{array}{l}\text { Height of neural spine divided by centrum height for } \\
\text { anterior caudal vertebra. Anterior caudal vertebrae were } \\
\text { considered to span first through fourth caudals. First } \\
\text { caudal vertebra was measured when available. When } \\
\text { unavailable, anterior-most available vertebra was used. } \\
\text { Indicates potential dorsal lengthening of anterior portion } \\
\text { of tail. }\end{array}$ \\
\hline
\end{tabular}


Neural spine index for midway caudal vertebra (NSI-MCV)

Transverse process index for anterior caudal vertebra (TPI-ACV)

llium index (III)

Pubis index (Publ)

Ischium index (Ischl)

Ilium-Ischium Index (II-Isch)

Ilium-Pubis Index (II-Pub)

Ischium-Pubis Index (Isch-Pub)
Height of neural spine divided by centrum height for midway caudal vertebra. Midway caudal vertebrae were selected from the halfway point of the total tail length for each specimen. Indicates potential dorsal lengthening of midway portion of tail.

Total length of transverse processes divided by centrum length for anterior caudal vertebra. Anterior caudal vertebrae were considered to span first through fourth caudals. First caudal vertebra was measured when available. When unavailable, anterior-most available vertebra was used. Indicates presence of mediolateral compression.

Ilium length divided by ilium width (IIL/IW). Indicator of relative width of ilium available for muscle attachment. Pubis length divided by pubis width (PubL/PubW). Indicator of relative width of pubis available for muscle attachment.

Ischium length divided by ischium width (IschL/IschW). Indicator of relative width of ischium available for muscle attachment.

Ilium length divided by ischium length (IIL/IschL). Displays relative areas of attachment for various hindlimb, trunk, and tail muscles such as the caudofemoralis, iliocostalis, and ilio-ischio-caudalis.

Ilium length divided by pubis length (IIL/PubL). Displays relative areas of attachment for various muscles such as the ischiopubis and iliocostalis. Ischium length divided by pubis length (IschL/PubL). Detects presence of posterior expansion of the pelvis for attachment of tail muscles.

Measurements indicated above are described in Table 1 and illustrated in Figure 1. Definitions and hypothesized functional meaning of indices are included. Several indices are based on those described in Samuels and Van Valkenburg 2008.

As an alternative method to correct for body size and account for the influence of allometry, geometric mean (GM), calculated as the $n^{\text {th }}$ root of the product of $n$ measurements, was computed for each specimen as a proxy for body size (Mossiman and James 1979). The resulting GM score was then used to calculate a set of GM transformed variables (variable/GM $=$ transformed) from each of the linear measurements, which yield variables corrected for individual body size (Mossiman and James 1979). Additionally, the GM score itself can be used 
to study allometry, by regressing other variables (log transformed linear measurements and indices) against log GM score and examining whether slopes are significantly different from isometry (z test).

\section{$\underline{\text { Statistical Analyses }}$}

Univariate Analysis of Variance (ANOVA) and boxplots were used to assess whether there are significant differences in the osteological indices between locomotor groups and to visualize these differences. I also conducted a stepwise discriminant function analysis (DFA) using the osteological indices to identify which variables can be used to best distinguish between terrestrial, semi-aquatic, and arboreal reptiles. An additional DFA was conducted using GM transformed variables. The DFA based on GM scores is expected to highlight aspects of morphology that best separate groups, while correcting for body size.

The discriminant functions derived from the analysis using osteological indices were then used to infer the locomotor mode of extinct crocodylomorph taxa, which were included as unknowns in the classification phase of the analysis. As osteological indices are easily calculated, even from fragmentary specimens, that analysis has the greatest potential to include and classify the locomotion of extinct species. Ideally, the DFA based on GM scores would also be used to classify the locomotor habits of extinct species, but that would require particularly complete specimens, as all variables are needed to calculate the GM score.

Linear regressions and bivariate plots were also performed on log GM scores versus log transformed linear measurements and osteological indices that displayed significance within the DFAs. Deviations of slopes from expectations (allometry) were tested using a z-test. Zscores were calculated by subtracting the expected slope from the observed slope produced by 
the least squares linear regressions and dividing this by the standard error of the slope. These analyses allowed examination of interspecific allometry and how body size may have an impact on morphological features that distinguish locomotor groups. All statistical analyses were done in IBM SPSS Statistics 24. 


\section{CHAPTER 4}

\section{RESULTS}

\section{ANOVA Results}

The univariate ANOVA (Table 6) aided in identifying several indices that help to distinguish between our locomotor groups. Select indices have been highlighted via the boxplots in Figure 2. The semi-aquatic reptile taxa display a more elongate ischium (high IschPub, low II-Isch), a short and broad ilium and pubis (III and PubI) and a more elongate scapula (high PFI) relative to the other two groups. Arboreal taxa generally showed more slender, gracile limbs (low HPRI, HDRI, FRI, and TRI).

Table 6: Mean values and standard deviations of indices for each locomotor group

\begin{tabular}{|c|c|c|c|}
\hline & Terrestrial & Semi-aquatic & Arboreal \\
\hline $\mathrm{PFI}$ & $0.396(0.057)^{\mathrm{Sa}}$ & $0.578(0.175)^{\mathrm{T}, \mathrm{A}}$ & $0.374(0.091)^{\mathrm{Sa}}$ \\
\hline HRI & $0.091(0.0242)$ & $0.098(0.020)^{A}$ & $0.069(0.017)^{\mathrm{Sa}}$ \\
\hline HPRI & $0.274(0.046)^{A}$ & $0.256(0.035)$ & $0.213(0.041)^{\top}$ \\
\hline HDRI & $0.305(0.068)^{A}$ & $0.273(0.052)$ & $0.226(0.067)^{\top}$ \\
\hline SMI & $0.286(0.059)$ & $0.295(0.069)$ & $0.239(0.076)$ \\
\hline $\mathrm{BI}$ & $0.837(0.078)^{\mathrm{sa}}$ & $0.783(0.070)^{\top}$ & $0.824(0.058)$ \\
\hline $\mathrm{B} 12$ & $0.743(0.067)^{\mathrm{Sa}}$ & $0.694(0.069)^{\top}$ & $0.739(0.057)$ \\
\hline $\mathrm{MFI}$ & $0.890(0.053)$ & $0.886(0.031)$ & $0.897(0.019)$ \\
\hline $\mathrm{Cl}$ & $0.810(0.096)$ & $0.764(0.058)$ & $0.797(0.074)$ \\
\hline FRI & $0.088(0.022)^{A}$ & $0.090(0.020)^{A}$ & $0.064(0.021)^{\mathrm{T}, \mathrm{Sa}}$ \\
\hline IMI & $0.812(0.082)$ & $0.775(0.083)$ & $0.795(0.131)$ \\
\hline TRI & $0.091(0.023)^{A}$ & $0.095(0.023)^{A}$ & $0.065(0.026)^{\mathrm{T}, \mathrm{Sa}}$ \\
\hline $\mathrm{BLI}$ & $0.464(0.212)$ & $0.410(0.169)$ & $0.283(0.071)$ \\
\hline NSI-ACV & $1.937(0.619)$ & $2.356(1.074)$ & $2.451(0.985)$ \\
\hline NSI-MCV & $2.032(1.417)$ & $2.878(1.326)$ & $1.613(1.041)$ \\
\hline TPI-ACV & $3.415(0.623)$ & $3.121(0.447)$ & $3.028(0.378)$ \\
\hline III & $2.679(0.476)^{\mathrm{Sa}}$ & $2.201(0.669)^{\top, A}$ & $2.939(0.303)^{\text {Sa }}$ \\
\hline Publ & $5.539(2.157) \mathrm{Sa}$ & $3.383(2.282)^{\mathrm{T}, \mathrm{A}}$ & $6.131(1.114)^{\mathrm{Sa}}$ \\
\hline Ischl & $1.671(1.183)$ & $2.034(1.363)$ & $1.308(0.168)$ \\
\hline II-Isch & $1.516(0.277)^{\mathrm{Sa}}$ & $1.260(0.324)^{\mathrm{T}, \mathrm{A}}$ & $1.687(0.272)^{\mathrm{Sa}}$ \\
\hline II-Pub & $1.230(0.212)$ & $1.266(0.234)$ & $1.199(0.248)$ \\
\hline Isch-Pub & $0.822(0.124)^{\mathrm{Sa}}$ & $1.036(0.187)^{\mathrm{T}, \mathrm{A}}$ & $0.712(0.112)^{\mathrm{Sa}}$ \\
\hline
\end{tabular}



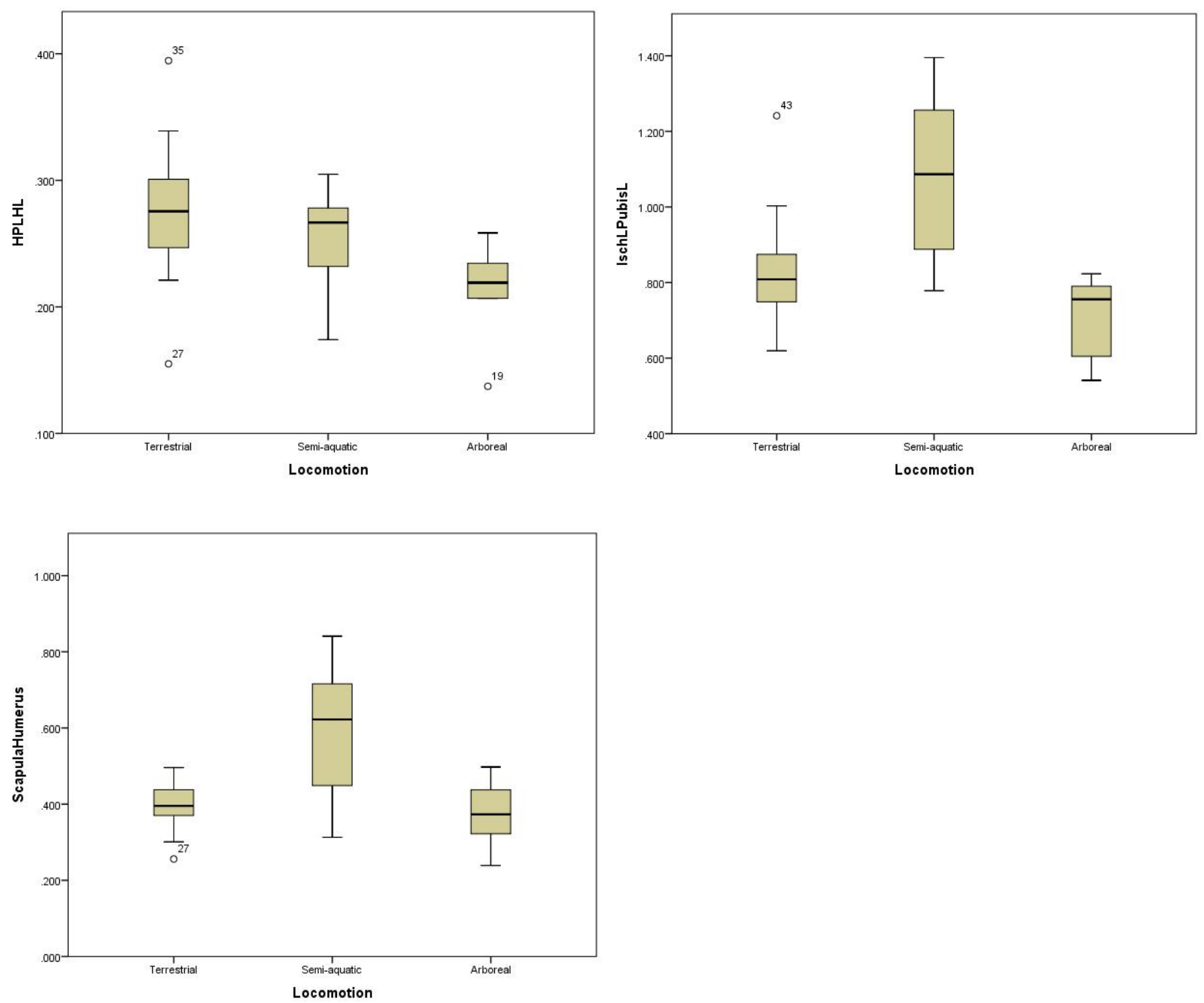

Figure 2: Boxplots of functional indices

The bar displays the median, boxes represent upper and lower quartiles, and whiskers show extreme values for each group. Outliers are represented by individual circles with species numbers (Table 1).

\section{DFA Using Osteological Indices (Indices DFA)}

The stepwise DFA using osteological indices (Indices DFA) included four of the total 22 indices and showed significant separation of locomotor groups based on their morphology (Wilks' lambda $=0.279)$ (Table 7). The analysis yielded two discriminant functions, the first of which (DF1) accounted for $81.9 \%$ of variance and largely separated the terrestrial and semiaquatic groups. DF1 showed strong negative correlation with PFI (Scapula length to humerus 
length) and Isch-Pub (Ischium length to pubis length), but slight positive correlation with Crural Index (Tibia length to femur length) and HPRI (Humerus proximal breadth to humerus length) (Table 7). Terrestrial taxa tended toward more positive scores while semi-aquatic taxa tended toward more negative scores. This indicates the tendency for semi-aquatic reptile species to have a shorter proximal forelimb relative to scapula length, a shorter distal hindlimb, a longer ischium, and a more narrow proximal humerus.

The second discriminant function (DF2) accounted for $18.1 \%$ of variance and primarily distinguished arboreal taxa from the terrestrial and semi-aquatic groups. DF2 showed a highly positive correlation with $\mathrm{HPRI}$ as well as a somewhat positive correlation with $\mathrm{Cl}$ and Isch-Pub (Table 7, Figure 3). Arboreal taxa tended toward slightly more negative scores than either terrestrial or semi-aquatic taxa, indicating the tendency for arboreal taxa to have a more narrow proximal humerus relative to a longer overall humerus, a shorter distal hindlimb, and a shorter ischium relative to pubis length.

Table 7: Indices DFA structure matrix and summary statistics

\begin{tabular}{lll}
\hline & \multicolumn{2}{c}{ Function } \\
\hline & 1 & 2 \\
\hline $\mathrm{PFI}$ & -.643 & .375 \\
$\mathrm{HPRI}$ & .117 & .820 \\
$\mathrm{Cl}$ & .218 & -.051 \\
Isch-Pub & -.631 & .626 \\
Eigenvalue & 1.636 & .361 \\
\% Variance & 81.9 & 18.1 \\
Wilks' lambda & .279 & .735 \\
$\mathrm{p}$ & $<0.001$ & 0.002
\end{tabular}

All indices are defined in Table 5 (PFI, proximal forelimb index; HPRI, humeral proximal robustness index; $\mathrm{Cl}$, crural index; Isch-Pub, ischium-pubis index). 


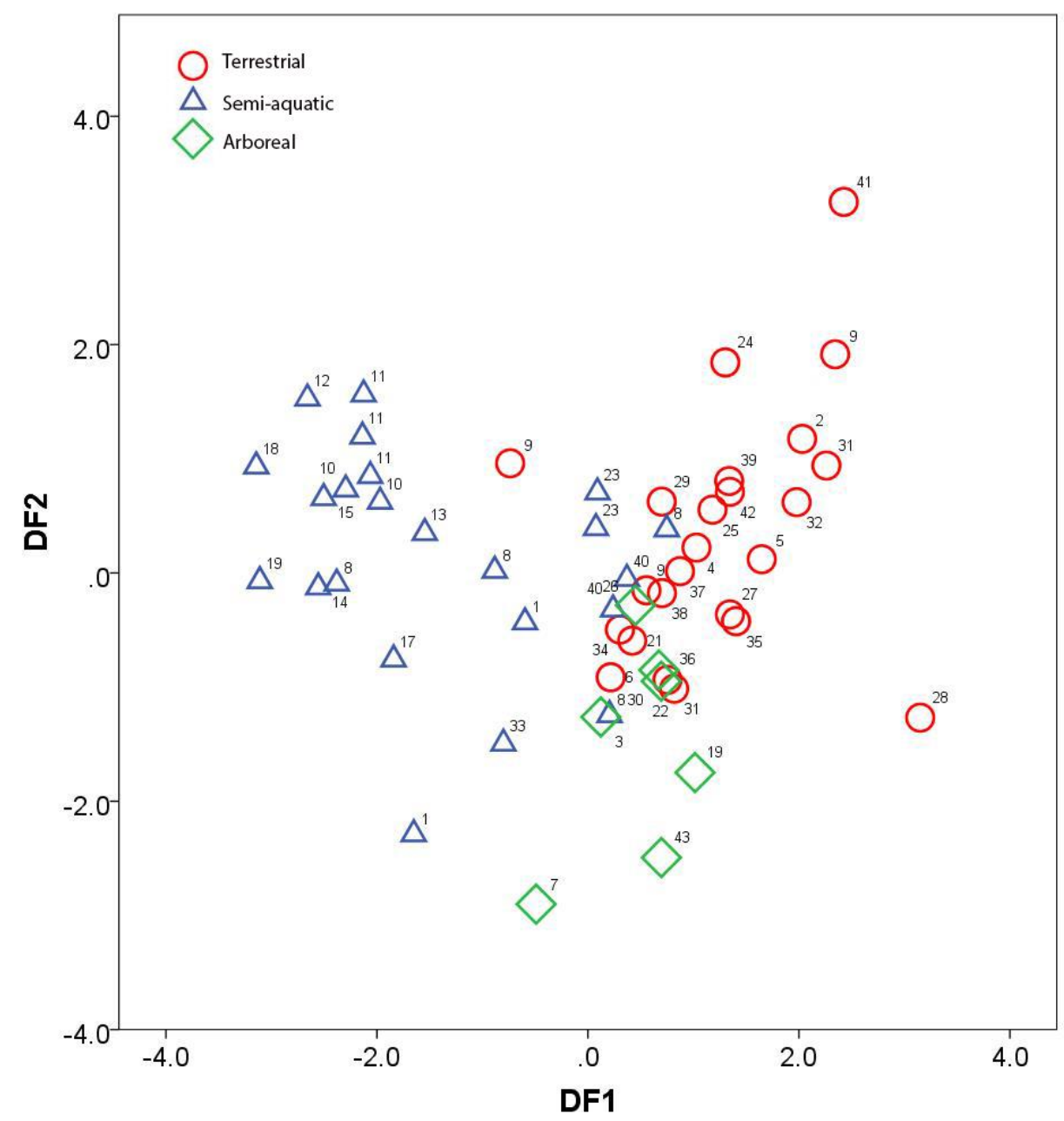

Figure 3: Plot of DF1 and DF2 scores for extant reptile taxa analyzed in the Indices DFA

\section{DFA Using Geometric Mean Transformed Variables (GM DFA)}

A stepwise DFA using the GM transformed variables (GM DFA) included only two of the 38 total transformed variables, but showed a significant separation of locomotor groups based on their morphology (Wilks' lambda $=0.540)($ Table 8, Figure 4). This analysis produced two discriminant functions (GM DF1 and GM DF2).

GM DF1 accounts for $90.7 \%$ of variance and primarily separates semi-aquatic taxa from terrestrial and arboreal taxa. GM DF1 displays a strong positive correlation with acetabulum 
diameter and a negative correlation with humerus proximal breadth (Table 8). Semi-aquatic taxa tend to have more positive scores than terrestrial and arboreal taxa.

GM DF2 accounts for $9.3 \%$ of variance and appears to do play little role in distinguishing between the locomotor groups. GMDF2 is strongly positively correlated with both humerus proximal breadth and acetabulum diameter (Table 8). Semi-aquatic taxa tend to have more negative scores than the other two locomotor groups

Table 8: GM DFA structure matrix and summary statistics

\begin{tabular}{lll}
\hline & \multicolumn{2}{c}{ Function } \\
\hline & 1 & 2 \\
\hline Trans_HPB & -.330 & .944 \\
Trans_AcetD & .795 & .606 \\
Eigenvalue & .723 & .074 \\
\% Variance & 90.7 & 9.3 \\
Wilks' lambda & .540 & .931 \\
$\mathrm{p}$ & $<0.001$ & 0.068
\end{tabular}

Definitions and illustrations of measurements are shown in Table 4 and Figure 1 (HPB, humeral proximal breadth; AcetD, acetabulum diameter). 


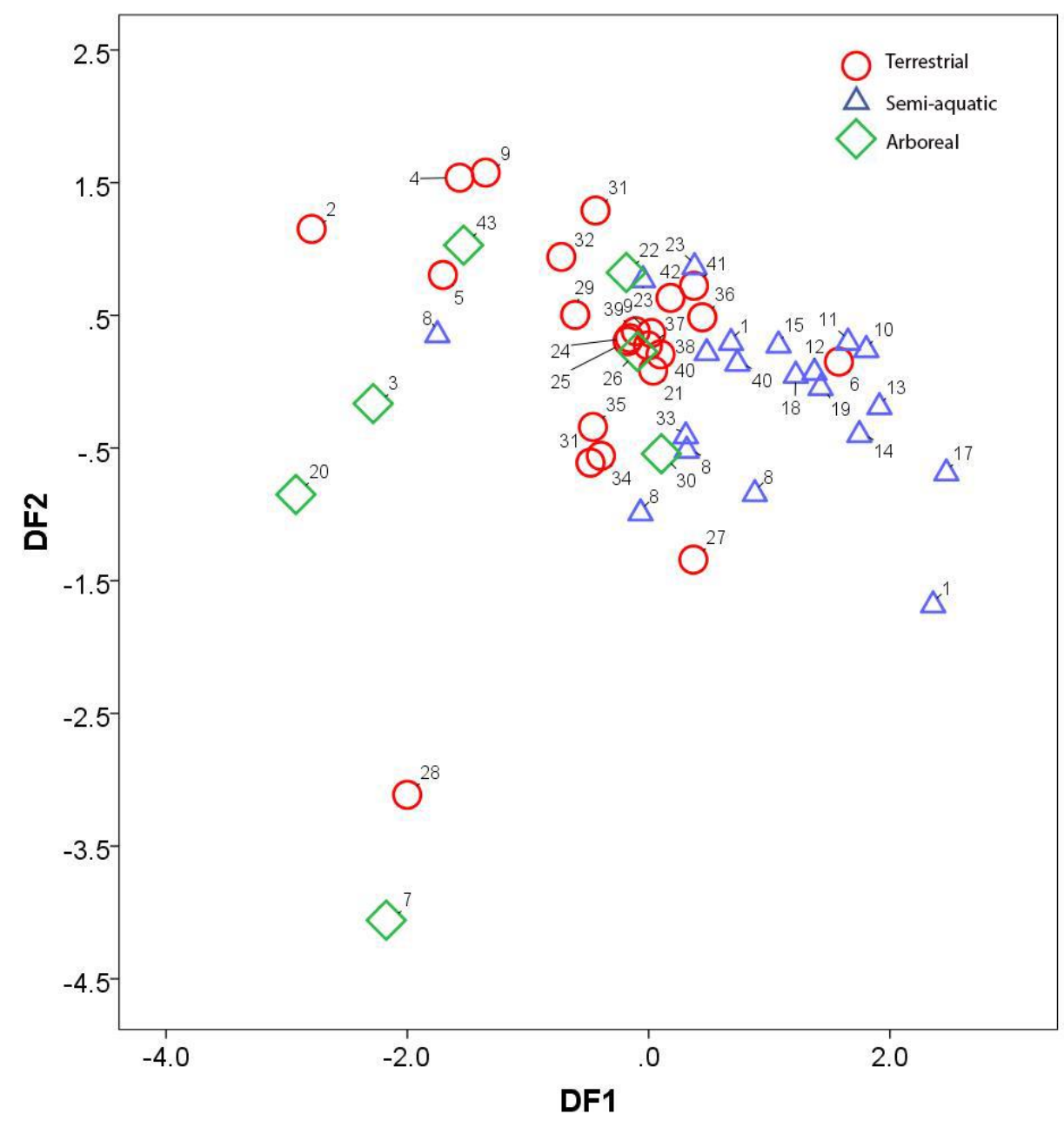

Figure 4: Plot of DF1 and DF2 scores for extant reptile taxa analyzed in the GM DFA $\underline{\text { Inferred Locomotor Modes of Extant Lepidosaur and Crocodylian Taxa }}$

The discriminant models' ability to sort the taxa by locomotor group was indicated by the classification matrices in which each specimen was grouped based on the models created using all other specimens.

The classification phase of the Indices DFA correctly classified $81.5 \%$ of the extant specimens into their a priori locomotor groups. When cross-validated, $75.9 \%$ of the specimens were correctly classified (Table 9). The terrestrial group displayed the highest level of correct 
classification at $95 \%$, while the semi-aquatic group was somewhat lower (74\% correct), and the arboreal group had much poorer performance (only 57\% correct).

A total of 10 out of the 54 specimens were misclassified (Table 10). One taxon, Physignathus sp., only partially misclassified with one specimen misclassifying as terrestrial, one misclassifying as arboreal, and the remaining two correctly classifying as semi-aquatic. Both specimens for the semi-aquatic Amblyrhyncus cristatus and Varanus salvator misclassified as terrestrial. Three arboreal taxa misclassified as terrestrial including Iguana iguana, Enyalioides oshaughnessyi, and Ctenosaurua acanthura. One terrestrial taxon, Uromastyx aegypticus, misclassified as semi-aquatic.

Table 9: Indices DFA classification matrix

\begin{tabular}{|c|c|c|c|c|c|c|}
\hline & \multicolumn{6}{|c|}{ Predicted group membership } \\
\hline & $\begin{array}{l}\text { Observed } \\
\text { group }\end{array}$ & $\%$ correct & Terrestrial & $\begin{array}{l}\text { Semi- } \\
\text { aquatic }\end{array}$ & Arboreal & Total \\
\hline \multirow[t]{3}{*}{ Original } & Terrestrial & 95.8 & 23 & 1 & 0 & 24 \\
\hline & $\begin{array}{l}\text { Semi- } \\
\text { aquatic }\end{array}$ & 73.9 & 5 & 17 & 1 & 23 \\
\hline & Arboreal & 57.1 & 3 & 0 & 4 & 7 \\
\hline \multirow[t]{3}{*}{ Cross-validated } & Terrestrial & 87.5 & 21 & 1 & 2 & 24 \\
\hline & $\begin{array}{l}\text { Semi- } \\
\text { aquatic }\end{array}$ & 69.6 & 5 & 16 & 2 & 23 \\
\hline & Arboreal & 57.1 & 3 & 0 & 4 & 7 \\
\hline
\end{tabular}


Table 10: Indices DFA misclassified cases

\begin{tabular}{lcll}
\hline & $\boldsymbol{n}$ misclassified & Actual Group & Predicted Group \\
\hline Amblyrhyncus cristatus & 2 of 2 & Semi-aquatic & Terrestrial \\
Iguana iguana & 1 of 1 & Arboreal & Terrestrial \\
Enyalioides oshaughnessyi & 1 of 1 & Arboreal & Terrestrial \\
Ctenosaura acanthura & 1 of 1 & Arboreal & Terrestrial \\
Varanus salvator & 2 of 2 & Semi-aquatic & Terrestrial \\
Uromastyx aegypticus & 1 of 1 & Terrestrial & Semi-aquatic \\
Physignathus sp. & 2 of 4 & Semi-aquatic & 1 Terrestrial, 1 Arboreal
\end{tabular}

The classification phase of the GM DFA correctly classified $78.0 \%$ of the extant specimens into their a priori locomotor groups (Table 11). When cross-validated, $72.0 \%$ of the specimens were correctly classified. The terrestrial and semi-aquatic groups showed particularly high rates of correct classification (over $80 \%$ ), while the arboreal group had much poorer performance (only $57 \%$ correct).

Eleven of the 50 total taxa included within the GMDFA were misclassified (Table 12). Once again, both specimens of Amblyrhyncus cristatus misclassified as terrestrial and the arboreal taxa Iguana iguana, Enyalioides oshaughnessyi, and Ctenosaurua acanthura misclassified as terrestrial. Physignathus sp. again displayed 50\% correct classification with two specimens misclassifying as terrestrial, however the specimen that previously misclassified as arboreal within DFA 1 correctly classified as semi-aquatic. Additionally, the terrestrial taxa Cordylus giganteus and Dipsosaurus dorsalis both misclassified as semi-aquatic while the arboreal Varanus beccarii misclassified as terrestrial. 
Table 11: GM DFA classification matrix

\begin{tabular}{|c|c|c|c|c|c|c|}
\hline & \multicolumn{6}{|c|}{ Predicted group membership } \\
\hline & $\begin{array}{l}\text { Observed } \\
\text { group }\end{array}$ & $\%$ correct & Terrestrial & $\begin{array}{l}\text { Semi- } \\
\text { aquatic }\end{array}$ & Arboreal & Total \\
\hline \multirow[t]{3}{*}{ Original } & Terrestrial & 87.0 & 20 & 2 & 1 & 23 \\
\hline & $\begin{array}{l}\text { Semi- } \\
\text { aquatic }\end{array}$ & 80.0 & 4 & 16 & 0 & 20 \\
\hline & Arboreal & 57.1 & 4 & 0 & 3 & 7 \\
\hline \multirow[t]{3}{*}{ Cross-validated } & Terrestrial & 78.3 & 18 & 3 & 2 & 23 \\
\hline & $\begin{array}{l}\text { Semi- } \\
\text { aquatic }\end{array}$ & 80.0 & 4 & 16 & 0 & 20 \\
\hline & Arboreal & 28.6 & 5 & 0 & 2 & 7 \\
\hline
\end{tabular}

Table 12: GM DFA misclassified cases

\begin{tabular}{llll}
\hline Species & $\boldsymbol{n}$ misclassified & Actual Group & Predicted Group \\
\hline Cordylus giganteus & 1 of 1 & Terrestrial & Semi-aquatic \\
Amblyrhyncus cristatus & 2 of 2 & Semi-aquatic & Terrestrial \\
Iguana iguana & 1 of 1 & Arboreal & Terrestrial \\
Dipsosaurus dorsalis & 1 of 1 & Terrestrial & Semi-aquatic \\
Enyalioides oshaughnessyi & 1 of 1 & Arboreal & Terrestrial \\
Callisaurus draconoides & 1 of 1 & Terrestrial & Arboreal \\
Ctenosaura acanthura & 1 of 1 & Arboreal & Terrestrial \\
Physignathus sp. & 2 of 4 & Semi-aquatic & Terrestrial \\
Varanus beccarii & 1 of 1 & Arboreal & Terrestrial
\end{tabular}

Linear Regressions and Interspecific Allometry

The indices and GM transformed variables that were included in the DFAs have been further analyzed through bivariate plots and linear regressions to better visualize the differences in these variables across the locomotor groups. The linear regressions revealed the presence of positive allometry in acetabulum diameter, proximal forelimb index (PFI), humeral proximal robustness index (HPRI), and ischium-pubis index (Isch-Pub) (Figure 5). The plots 
shown in Figure 6 have been used to examine how each variable is contributing to the indices identified within the Indices DFA. These plots revealed that PFI appears to largely be driven by differences in scapula length, with a generally longer scapula present in semi-aquatic taxa relative to the other two groups (Figure 6h) while humerus length relative to body size is fairly uniform across groups (Figure 6g). Similarly, low HPRI values seen in semi-aquatic taxa seem to be the result of more slender proximal humerus compared to other taxa (Figure 6a), whereas the arboreal group's low values for HPRI appear to primarily be the result of a more elongate humerus (Figure 6g). Differences in femur length and tibia length appear to be minimal across the groups, indicating a low level of importance of the crural index in distinguishing locomotor preferences, although semi-aquatic taxa seem to trend toward slightly higher values for both (Figures 6e and 6f). The ischium-pubis index seems to be impacted by both variables with a generally longer ischium and shorter pubis in semi-aquatic taxa and a shorter ischium with a longer pubis in arboreal taxa (Figures $6 c$ and $6 d$ ). Figure 7 then displays plots of each individual index, allowing for visual comparisons of additional fossil taxa that could not be incorporated in the original discriminant function analysis due to lack of material. 

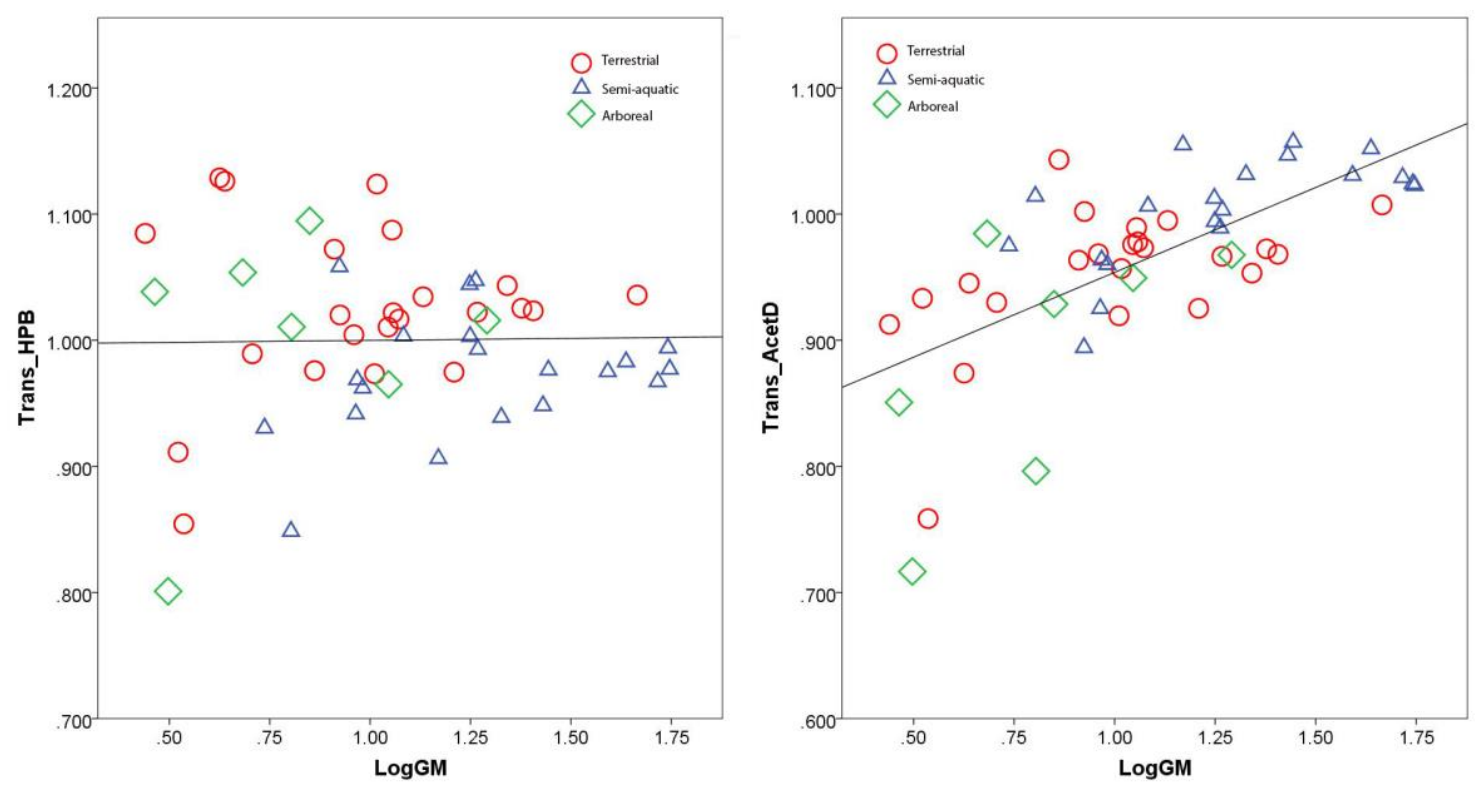

a

b
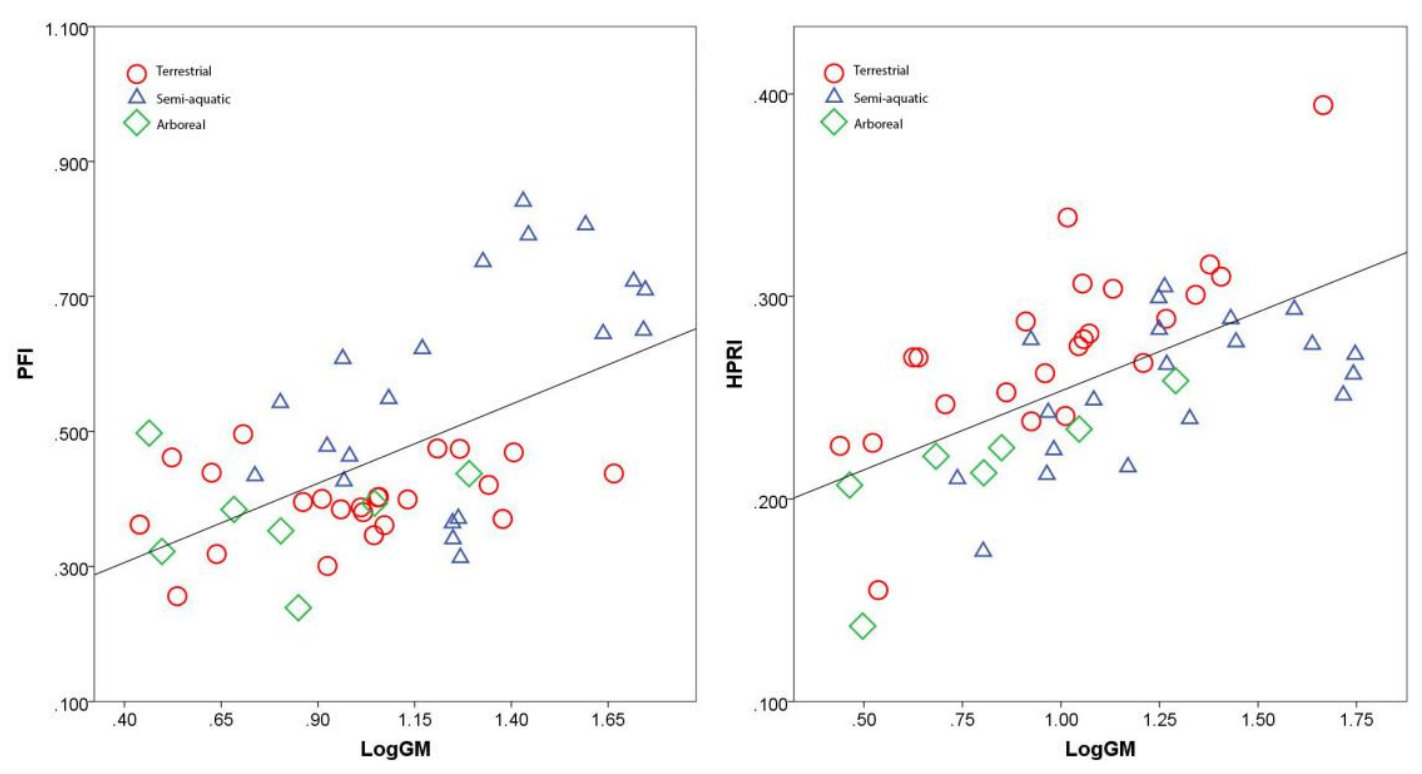

C

d 


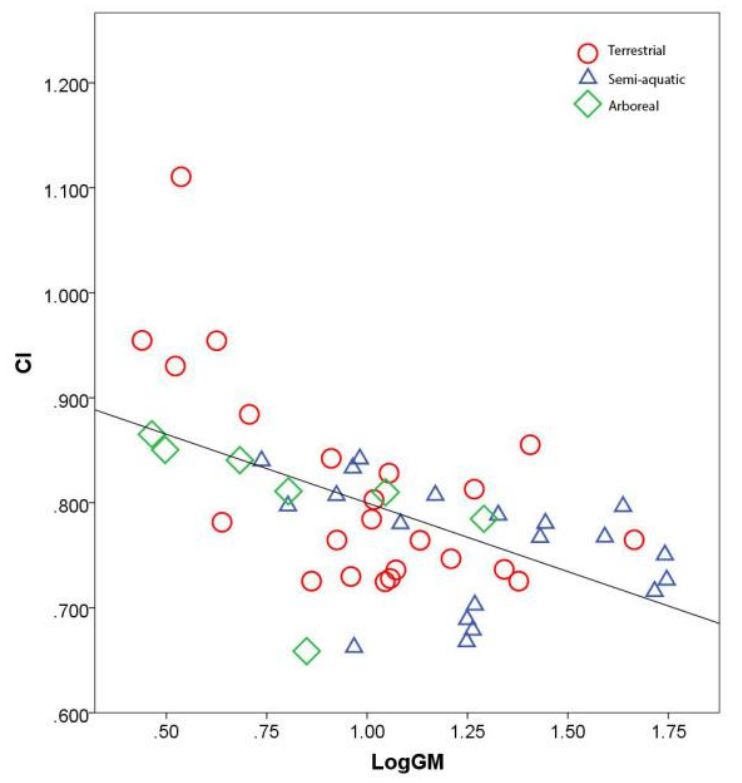

e

Figure 5: Plots of selected functional indices and GM transformed variables versus the log geometric mean (a proxy for body size).

a: Humerus proximal breadth. Total fit line: $y=1+3.17 E-3^{*} x$. b: Acetabulum diameter. Total fit line: $y=0.82+0.13^{*} x$. c: Proximal forelimb index. Total fit line: $y=0.21+0.23^{*} x$. d: Humeral proximal robustness index. Total fit line: $y=0.18+0.08^{*} x$. e: Crural index. Total fit line: $y=0.93-$ $0.13^{*} x$. f: Ischium pubis index. Total fit line (solid): $y=0.49+0.37^{*} x$. Semi-aquatic fit line (dashed): $y=0.47+0.45 * x$

Table 13: Z-scores displaying the influence of allometry on variables identified by the DFAs

\begin{tabular}{llll}
\hline Variable & Observed Slope & Std. Error of Slope & Z-Score \\
\hline PFI & 0.006416 & 0.001203 & 5.33 \\
HPRI & 0.001542 & 0.000400 & 3.86 \\
Cl & -0.002167 & 0.000810 & -2.68 \\
Isch-Pub & 0.010159 & 0.001513 & 6.71 \\
Trans_HPB & -0.000205 & 0.000695 & -0.29 \\
Trans_AcetD & 0.002703 & 0.000618 & 4.37
\end{tabular}

Z-scores were calculated by subtracting the expected slope $(0)$ from the observed slope produced by the least squares linear regressions and dividing this by the standard error of the slope. Z-scores greater than 2 indicate positive allometry, while scores less than -2 indicate negative allometry. 

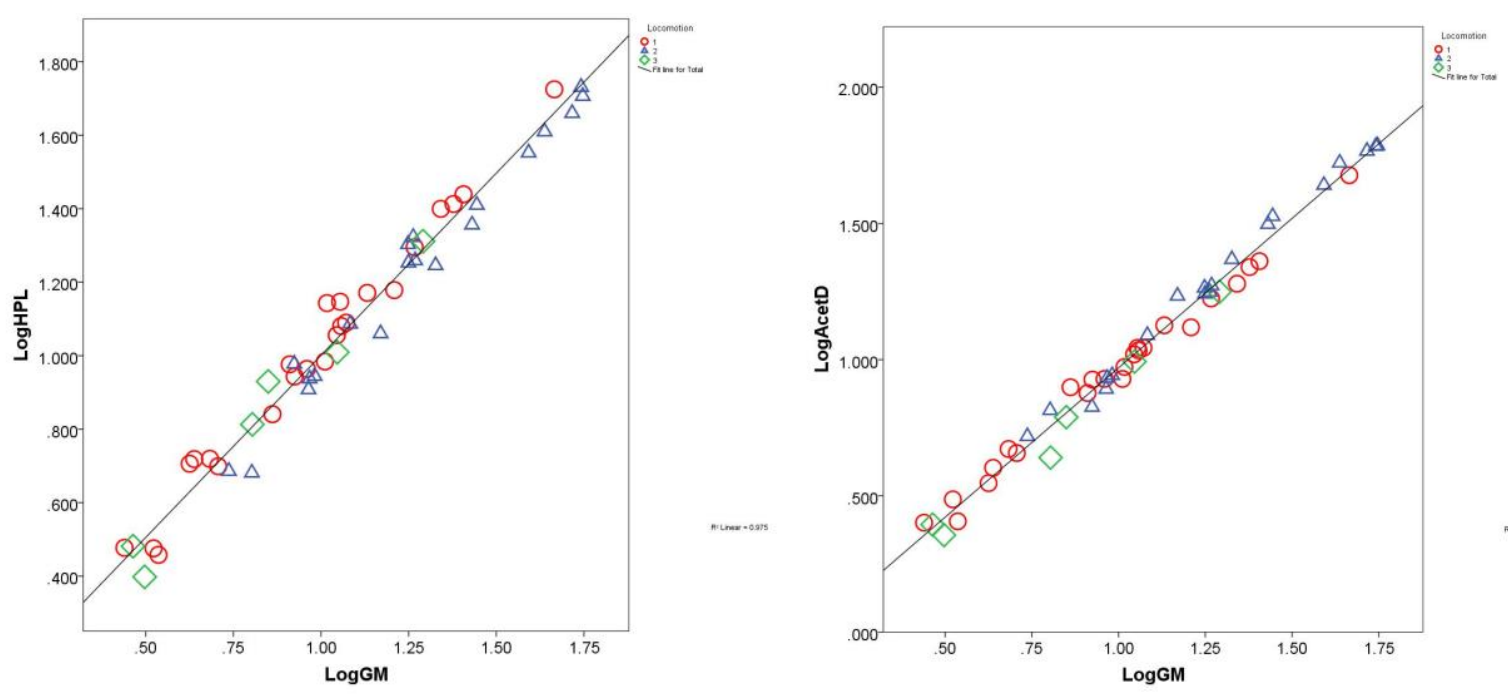

a

b

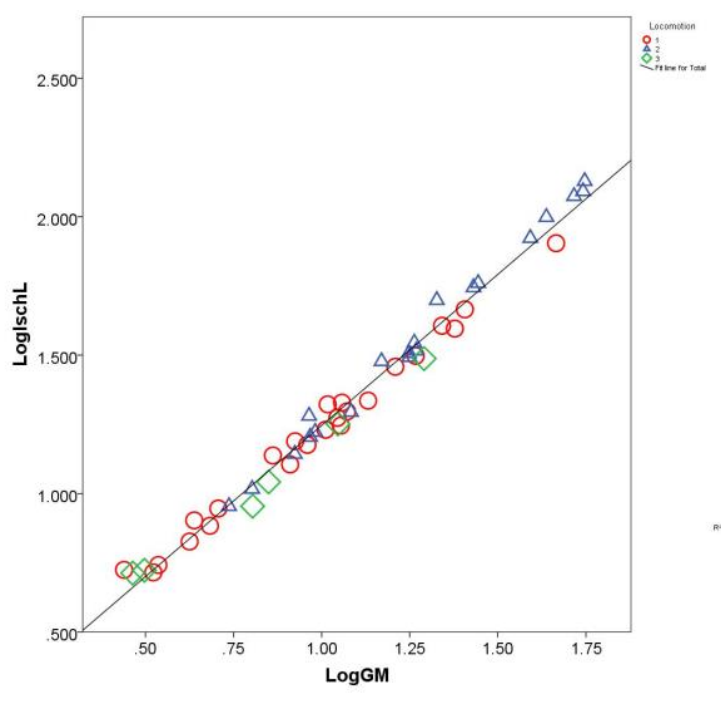

c

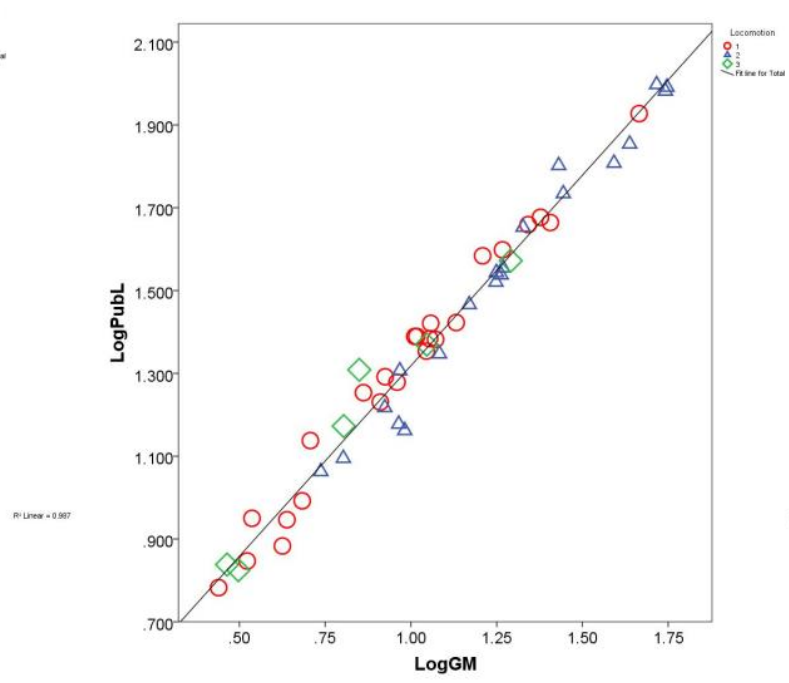

d 


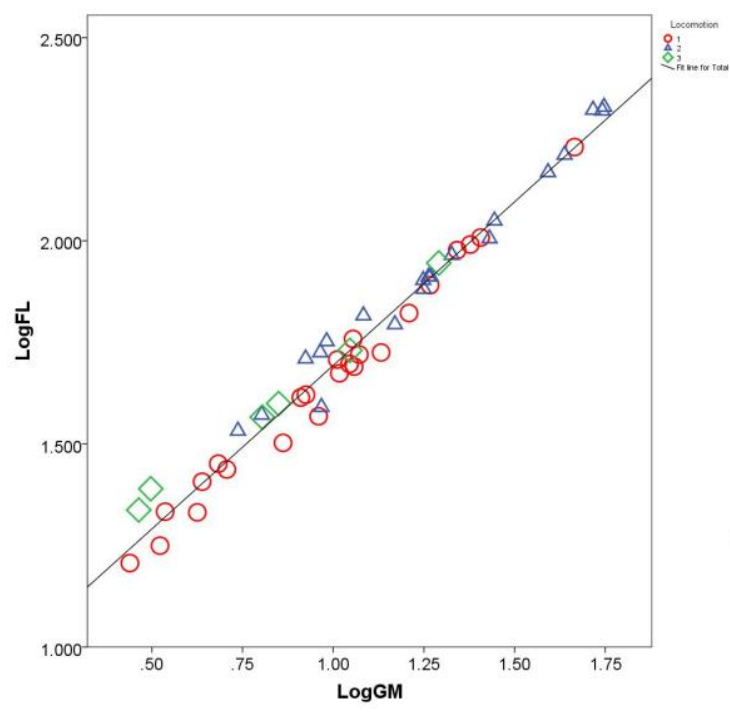

e

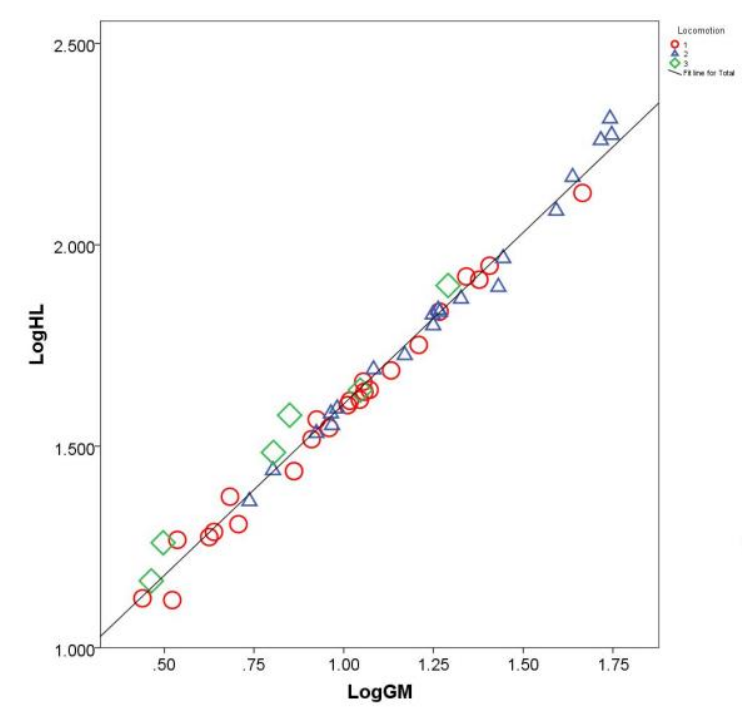

g

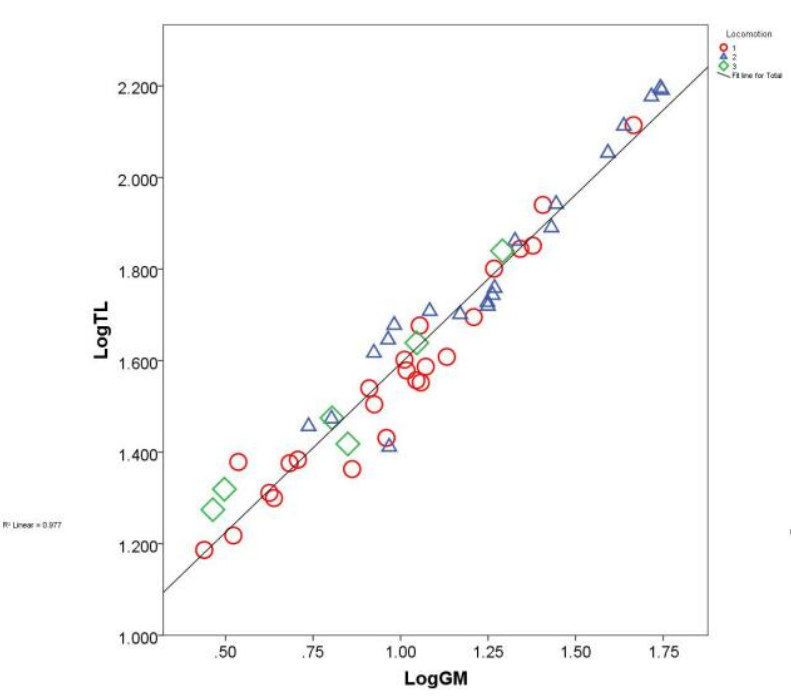

f

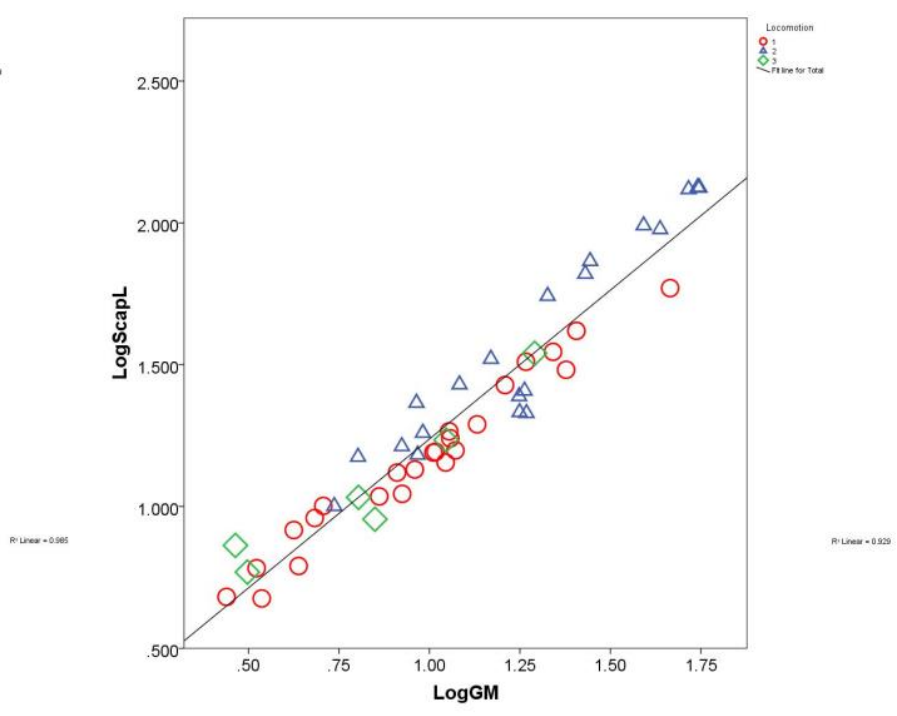

h

Figure 6: Log/log plots of variable components that displayed significance within the Indices DFA and the GM DFA

Individual points represent individual specimens included in the analysis. a: Humerus proximal breadth. Regression line: $y=9.54 E-3+0.88 * x$. Standard error of the estimate $=0.056$. Correlation coefficient $r=0.987$. b: Acetabulum diameter. Regression line: $y=-0.13+1.1^{*} x$. Standard error of the estimate $=0.043$. Correlation coefficient $r=0.994$. $c$ : Ischium length. Regression line: $y=$ $0.15+1.09 * x$. Standard error of the estimate $=0.044$. Correlation coefficient $r=0.993$. $d$ : Pubis length. Regression line: $y=0.4+0.92 * x$. Standard error of the estimate $=0.050$. Correlation coefficient $r=0.988$. e: Femur length. Regression line: $y=0.89+0.81^{*} x$. Standard error of the estimate $=0.044$. Correlation coefficient $r=0.988$. $f$ : Tibia length. Regression line: $y=$ $0.86+0.74 * x$. Standard error of the estimate $=0.061$. Correlation coefficient $r=0.973 . \mathrm{g}$ : 
Humerus length. Regression line: $y=0.75+0.85^{*} x$. Standard error of the estimate $=0.037$. Correlation coefficient $r=0.993$. $h$ : Scapula length. Regression line: $y=0.19+1.05 * x$. Standard error of the estimate $=0.103$. Correlation coefficient $r=0.964$.
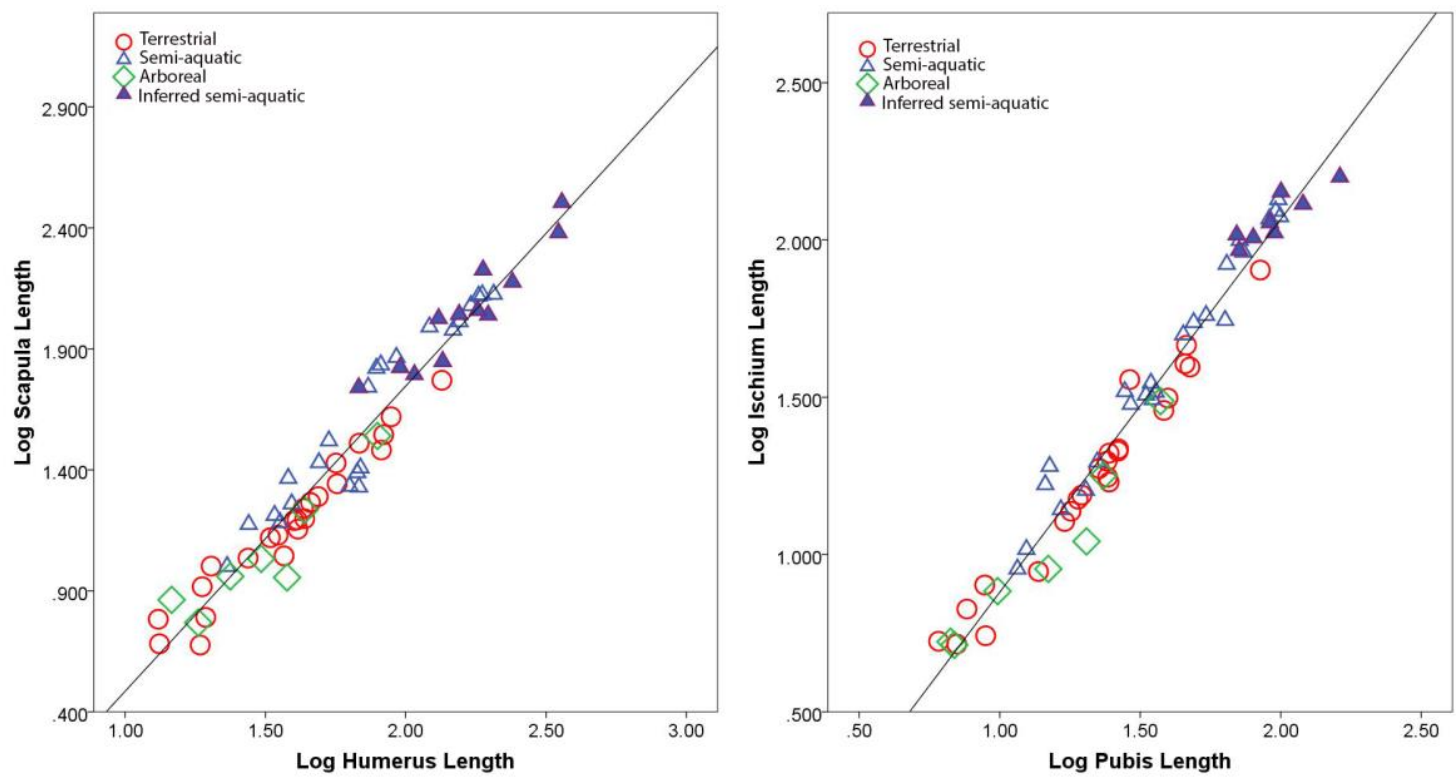

a
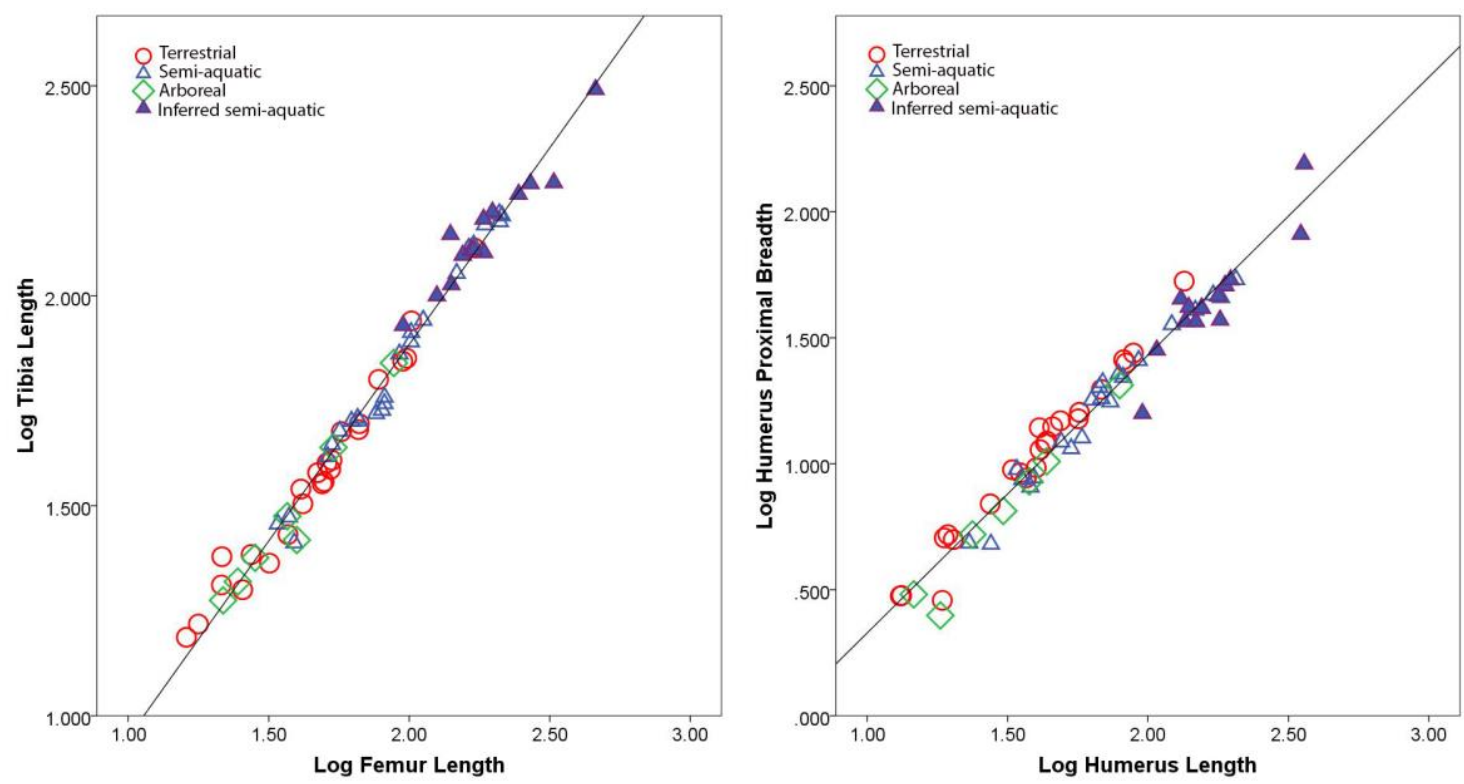

C

d

Figure 7: Log/log plots of indices components

The $y$-axis represents the numerator and the $x$-axis represents the denominator. Units are in log $(\mathrm{mm})$. a: Proximal forelimb index (PFI). Regression line: $y=-0.78+1.26 * x$. Standard error of the estimate $=0.038$. Correlation coefficient $r=0.983$. b: Ischium Pubis Index (Isch-Pub). Regression line: $y=0.31+1.19^{*} x$. Standard error of the estimate $=0.027$. Correlation coefficient $r=0.984$. $c$ : 
Crural index $(\mathrm{Cl})$. Regression line: $y=0.01+0.94 * x$. Standard error of the estimate $=0.015$. Correlation coefficient $r=0.992$. $d$ : Humeral proximal robustness index (HPRI). Regression line: $y$ $=0.77+1.1 * x$. Standard error of the estimate $=0.026$. Correlation coefficient $r=0.983$.

\section{$\underline{\text { Inferred Locomotor Modes of Extinct Crocodylians }}$}

Five of the 18 examined fossil crocodylomorph taxa were classified into a locomotor group by the Indices DFA. All other fossil specimens lacked sufficient fossil material to be grouped. The five taxa presented include Hyposaurus rogersii, Necrosuchus ionensis, Alligator sp. of the Gray Fossil Site, Crocodylus affinis, and Allognathosuchus mooki. All five were inferred to be semi-aquatic based on their negative values for DF1 within the Indices DFA (Figure 8). These taxa also displayed high probabilities $(\geq 0.9)$ of belonging to the semi-aquatic group (Table 14).

Table 14: Indices DFA classification of extinct species

\begin{tabular}{|c|c|c|c|}
\hline Taxa & Predicted Group & $P(D \mid G)$ & $P(G \mid D)$ \\
\hline Hyposaurus rogersii & Semi-aquatic & 0.717 & 0.99294 \\
\hline Crocodylus affinis & Semi-aquatic & 0.343 & 0.99736 \\
\hline Allognathosuchus mooki & Semi-aquatic & 0.225 & 0.98436 \\
\hline Necrosuchus ionensis & Semi-aquatic & 0.490 & 0.91964 \\
\hline Alligator sp. & Semi-aquatic & 0.390 & 0.99769 \\
\hline \multicolumn{4}{|c|}{$\begin{array}{l}P(D / G) \text { represents the conditional probability of the observed canonical score, given } \\
\text { membership in the most likely group. } P(G / D) \text { represents the posterior probability that a case } \\
\text { belongs in the predicted group, given the sample used to create the discriminant model } \\
\text { (Samuels et al., 2013). }\end{array}$} \\
\hline
\end{tabular}




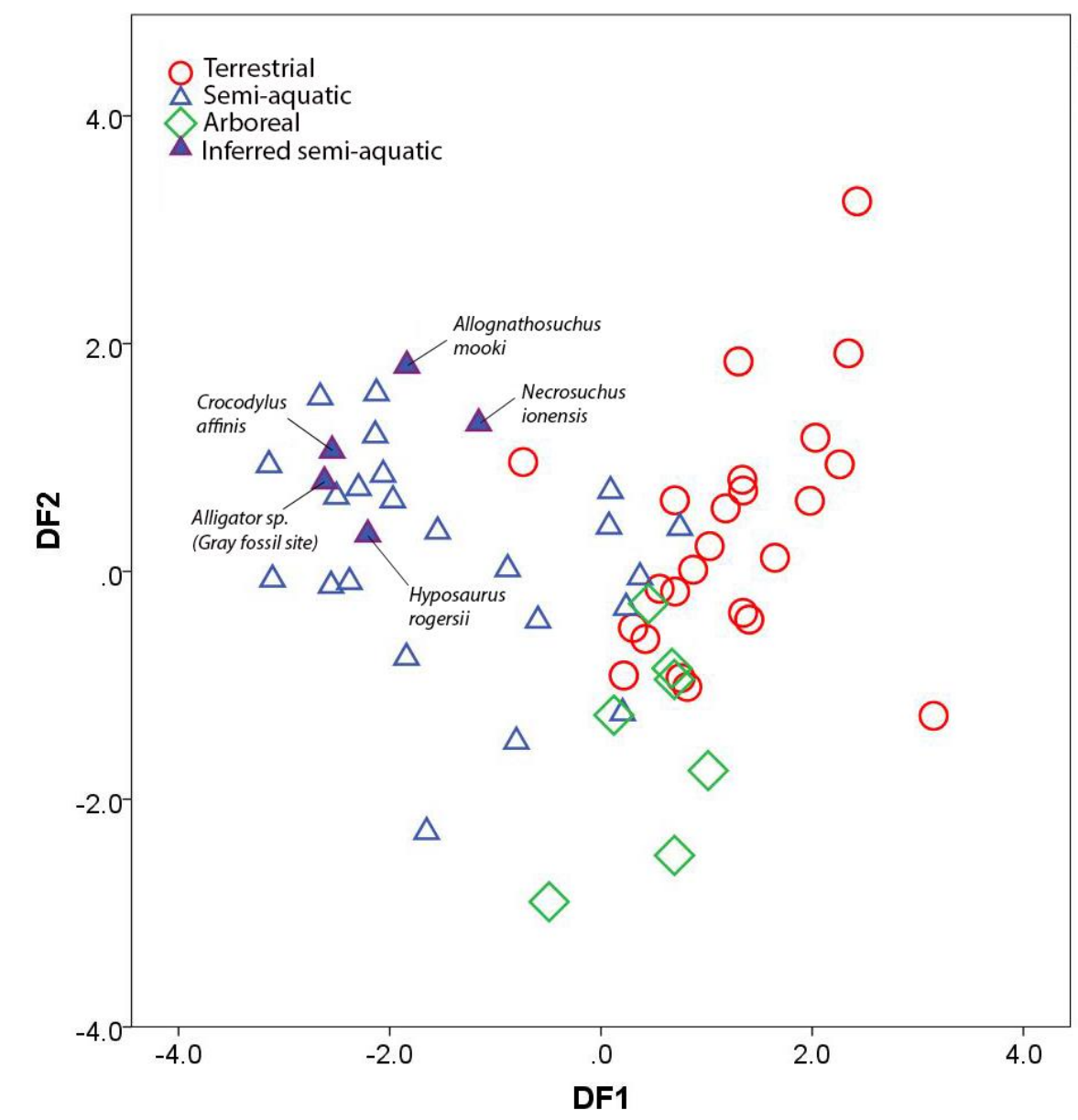

Figure 8: Plot of DF1 and DF2 discriminant scores for the Indices DFA including extinct taxa 


\section{CHAPTER 5}

\section{DISCUSSION}

While many modern reptiles are locomotor generalists and display a combination of

climbing, swimming, and terrestrial capabilities, there are several examples of species that have developed locomotor specializations. These specializations have evolved independently several times across multiple reptile lineages. Within this study, I found that convergent morphologies are present across reptile taxa utilizing similar locomotor modes, regardless of the distance in their evolutionary relationships. The locomotor groups each display significant morphological differences that allow these groups to be distinguished from one another. These distinctions also allowed for a high rate of success in correctly classifying members belonging to each of these groups.

Correlation of Postcranial Morphology with Locomotor Mode in Extant Crocodylians and Lepidosaurs

The statistical analyses conducted within this study revealed multiple features of the postcrania that enable us to differentiate between reptiles engaging in different locomotor behavior. The ANOVA and boxplots (Table 6, Figure 2) emphasize the utility of several of the indices in distinguishing between locomotor groups. The semi-aquatic group appeared to display the most deviations from both of the other two groups, potentially suggesting that semi-aquatic behavior requires more significant morphological adaptations.

Both discriminant function analyses had high degrees of success in distinguishing semiaquatic taxa from terrestrial and arboreal taxa, however grouping arboreal individuals proved to be more challenging. This may be the result of a limited sample size of arboreal lepidosaurs. In addition, many lepidosaurs are small-bodied generalists and thus are capable of a 
combination of scansorial and terrestrial locomotor behaviors without the need for extensive morphological adaptations, which may help to explain the overlap between these groups in morphospace. A more extensive examination of lepidosaur taxa that engage in higher degrees of arboreal behavior, such as chameleons and geckos, may aid in identifying morphological features indicative of this type of locomotion. Future analyses may also incorporate fossorial, saltatorial, and cursorial lepidosaurs to encompass an even broader range of morphological specializations (Vanhooydonck and van Damme 1999; Toro et al. 2004; Verwaijen and van Damme 2007).

The Indices DFA identified a variety of features as potential indicators of semi-aquatic behavior including longer scapulae (indicated by low values for PFI), a more slender proximal humerus (indicated by high values for HPRI) a slightly low crural index, and an elongated ischium (high values for ischium length to pubis length index).

The reduction of the proximal end of the humerus as well as the shortening of the distal hindlimb can aid these animals in holding their limbs close to the body to maintain a more streamlined body shape and thus reduce drag during aquatic locomotion (Stein 1988; Fish 1996; Gingerich 2003; O'Keefe and Carrano 2005). Unlike many aquatic mammals that utilize their limbs as the primary propulsive forces during swimming, reptiles instead tend to use their tails to generate thrust (Webb and Blake 1985). As a result, while several aspects of the limbs of semi-aquatic reptiles tend to be reduced as they do not require a high mechanical advantage, the tails require substantial muscle to drive their locomotion.

One of the muscles that forms the ventral wall of the tails in reptiles is the ilio-ischiocaudalis muscle (Mallison et al. 2015). A large portion of this muscle originates from the distal- 
most extent of the ischium and has been found to insert at the transverse processes and hemal spines of the caudal vertebra in several crocodylians (Persons and Currie 2013; Mallison et al. 2015). The larger length of the ischium encountered in semi-aquatic reptiles may be the result of increasing surface area for the attachment of this muscle to produce more powerful mediolateral undulations of the tail while in the water.

While the number of arboreal taxa included within the analysis was limited, certain morphological trends did appear to aid in characterizing the group. Arboreal specimens trended toward a longer, more slender humerus (low value for HPRI), a longer proximal hindlimb (low crural index), and a longer pubis (low value for Isch-Pub). The extended length of the proximal forelimb and hindlimb in arboreal taxa can allow for a longer reach while moving through branches of trees, while the more narrow proximal end of the humerus may indicate an overall thinner bone to promote speed and flexibility rather than supporting heavy muscle mass. A longer pubis relative to ischium length may be a manner of repositioning the center of gravity toward the center of the body to maintain better stability while climbing. It is important to note that while both semi-aquatic and arboreal taxa exhibit proximal reduction of the humerus, this adaptation is serving very different purposes in their locomotor behavior and thus should be examined with caution when inferring locomotor behaviors.

The GM DFA also identified semi-aquatic taxa as having a more gracile proximal humerus as well as a larger acetabulum diameter in comparison to terrestrial and arboreal reptiles. The broad acetabulum diameter encountered in semi-aquatic taxa may serve as an adaptation to improve terrestrial locomotion despite the group's many adaptations to movement in the water. This larger acetabulum may accommodate a larger femoral head that 
provides semi-aquatic taxa with more structural stability when carrying the weight of their heavily muscled tails during movement on land. Willey et al. (2003) found that the center of gravity of an alligator is focused closer to the hip than the shoulder joint. This may explain why we encounter proximal shortening in the forelimbs of semi-aquatic taxa, but relative distal shortening in the hindlimbs. The femur likely needs to remain a relatively significant size to be able to support the weight of a heavy, muscularized tail when on land compared to terrestrial taxa that have less musculature in that area.

\section{Assessment of Convergence in Lepidosaurs and Crocodylians}
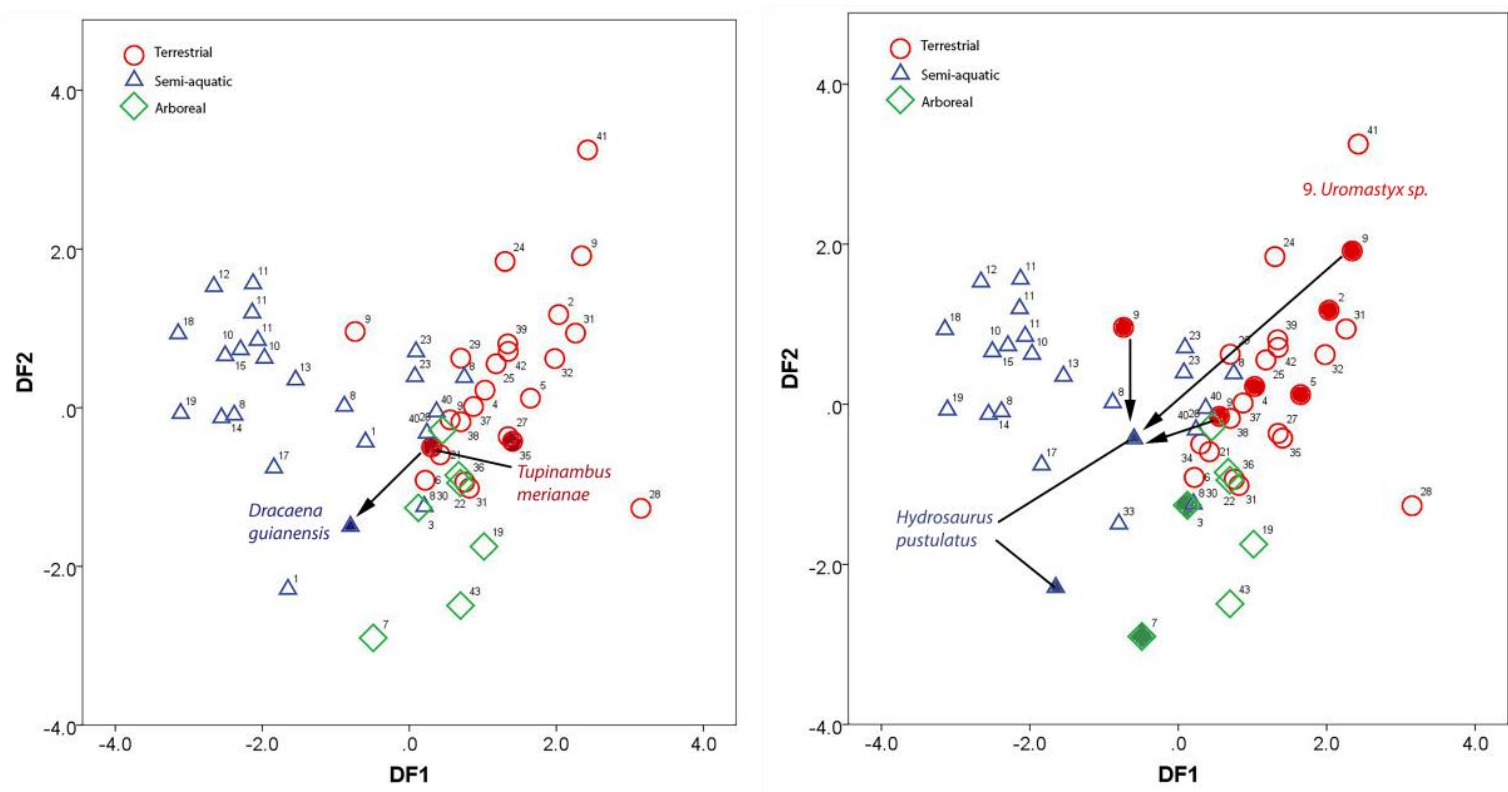

a

b 


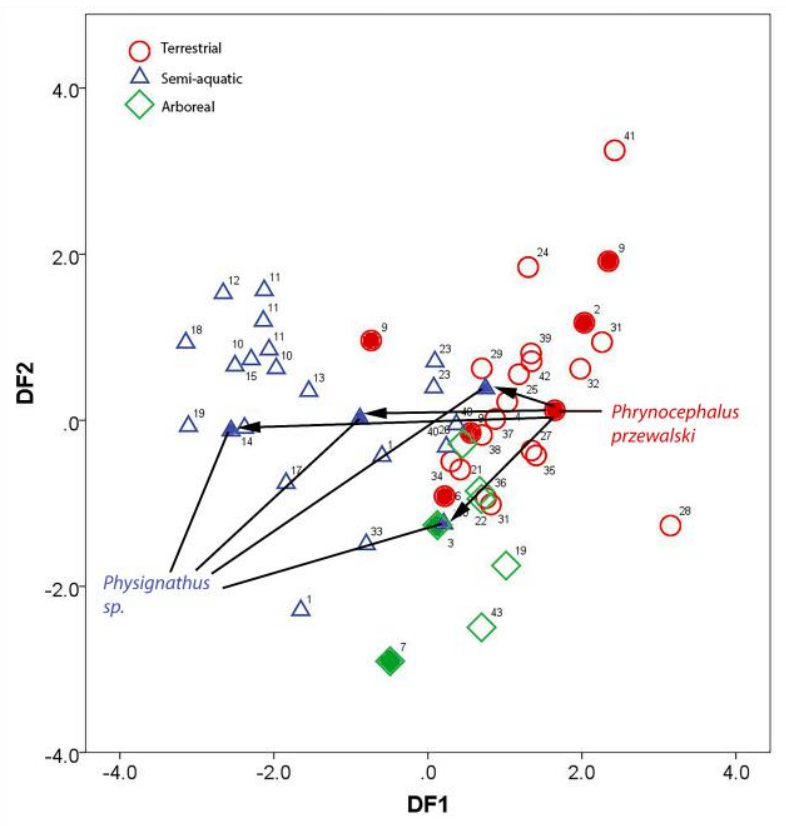

C

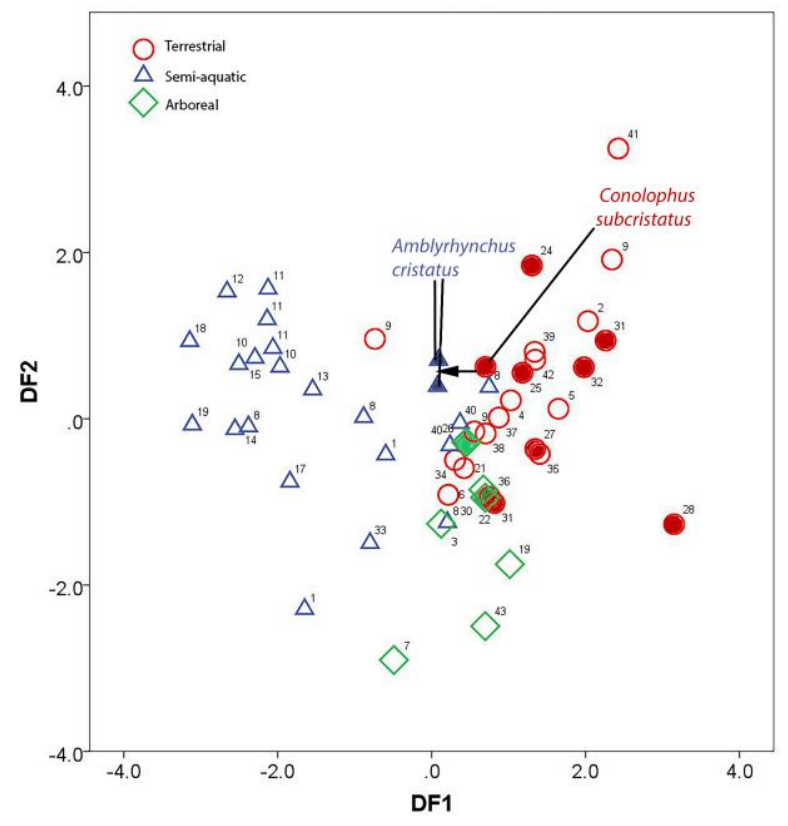

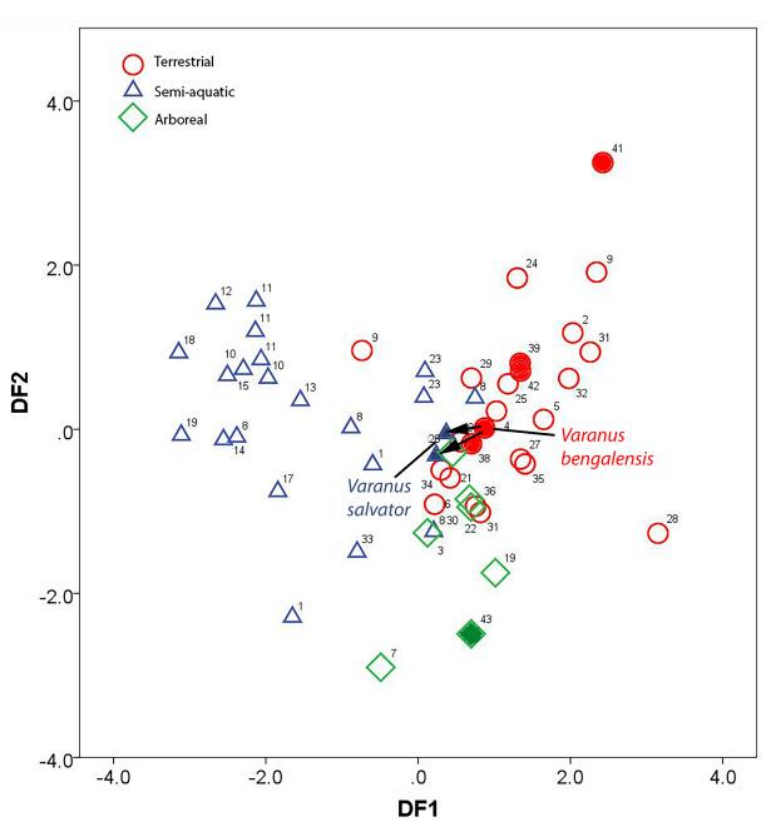

d

\section{e}

Figure 9: Plots of DF1 and DF2 scores for extant reptile taxa analyzed in the Indices DFA

Plots used to highlight divergence of semi-aquatic lepidosaur taxa from their terrestrial relatives. Within each plot, members belonging to the same family are represented by filled-in symbols. Arrows display the general direction of divergence in morphospace of semi-aquatic taxa from their closest terrestrial relative examined within the analysis. Relationships between taxa can be viewed in the phylogenies displayed in Figure 10. a: Teiidae; b. Agamidae, 
Hydrosaurus pustulatus; c. Agamidae, Physignathus sp.; d. Varanidae; e. Iguanidae

Several semi-aquatic lepidosaur taxa examined within this analysis appear to display convergence of morphological features with similarly semi-aquatic crocodylians. Members of Agamidae, Iguanidae, Teiidae, and Varanidae diverge in a similar direction from their terrestrial relatives.

Dracaena guianensis, the northern caiman lizard (Teiidae), was correctly classified as semi-aquatic, displaying a clear divergence in morphology from its terrestrial relatives (Figure 9a). Two specimens of Hydrosaurus pustulatus, the Phillipine sailfin lizard (Agamidae), were also correctly classified as semi-aquatic (Figure 9b). Out of four total Physignathus specimens, two properly classified as semi-aquatic while one misclassified as terrestrial and the other as arboreal. Specimens that were incorrectly classified, such as these two Physignathus, still displayed a divergence from the centroid in the same direction as other semi-aquatic taxa (Figure 9c). Both specimens of Amblyrhynchus cristatus and Varanus salvator were also misclassified as terrestrial; however, these specimens had relatively low discriminant scores for function one, trending closer toward the more negative scores characteristic of other semiaquatic taxa (Figures $9 \mathrm{~d}$ and 9e). Within the Indices DFA, one example of Uromastyx sp. is the only specimen to have misclassified as semi-aquatic. This taxon displays burrowing behavior (Nemtzov 2005) and suggests the future incorporation of a separate locomotor group for fossorial taxa could aid in discrimination of similar taxa.

The misclassification of several semi-aquatic lepidosaurs may be explained by an influence of allometry on semi-aquatic taxa. Figure 10 displays a plot of the specimens' discriminant function scores relative to their body size measured by the geometric mean. Both 
the terrestrial and arboreal groups have only slightly sloping lines and their z-scores are not significant (Table 15), indicating overall isometric growth. The semi-aquatic group, however, displays a clear negative slope and a z-score lower than -2 (Table 15) which indicates a significant deviation from isometry. With increases in body size come lower discriminant function scores as semi-aquatic adaptations appear to become more pronounced. Within the group of sampled Physignathus specimens, the two smaller individuals are those that misclassified while the larger specimens correctly classified as semi-aquatic. This may be related to larger individuals requiring more well-developed semi-aquatic adaptations.

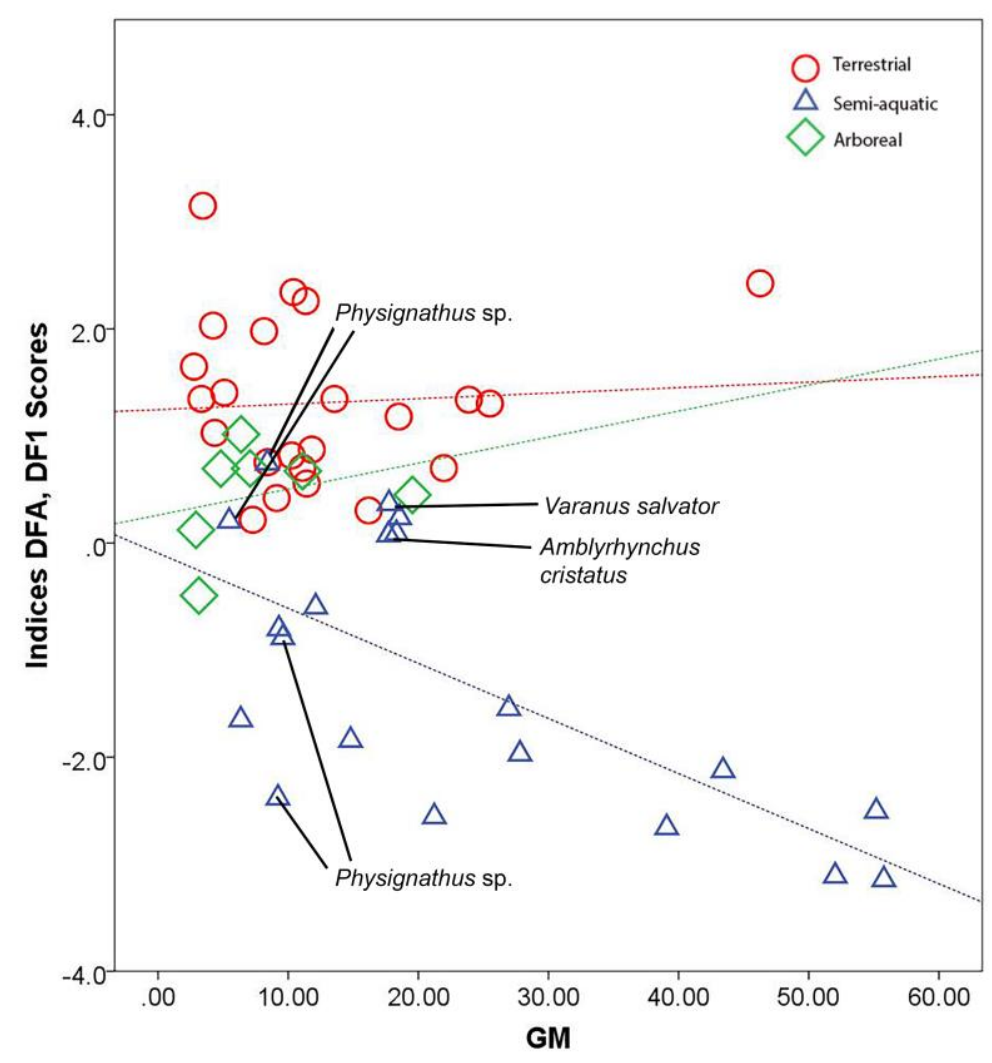

Figure 10: Plot of geometric mean versus DF1 scores of the Indices DFA

Terrestrial fit line (red dashed): $y=1.25+5.14 E-3^{*} x$. Semi-aquatic fit line (blue dashed): $y=-0.1-$ $0.05 * x$. Arboreal fit line ( $g r e e n$ dashed): $y=0.26+0.02 * x$. 
Table 15: Z-scores displaying the influence of allometry on different locomotor groups

\begin{tabular}{|c|c|c|c|}
\hline $\begin{array}{l}\text { Locomotor } \\
\text { Group }\end{array}$ & Observed Slope & Std. Error of Slope & Z-Score \\
\hline Terrestrial & 0.005144 & 0.016955 & 0.303 \\
\hline Semi-aquatic & -0.051461 & 0.013197 & -3.899 \\
\hline Arboreal & 0.024289 & 0.036333 & 0.669 \\
\hline \multicolumn{4}{|c|}{$\begin{array}{l}\text { Z-scores were calculated by subtracting the expected slope (0) from the observed slope } \\
\text { produced by the least squares linear regressions and dividing this by the standard error of the } \\
\text { slope. Z-scores greater than } 2 \text { indicate positive allometry, while scores less than - } 2 \text { indicate } \\
\text { negative allometry. }\end{array}$} \\
\hline
\end{tabular}


A)

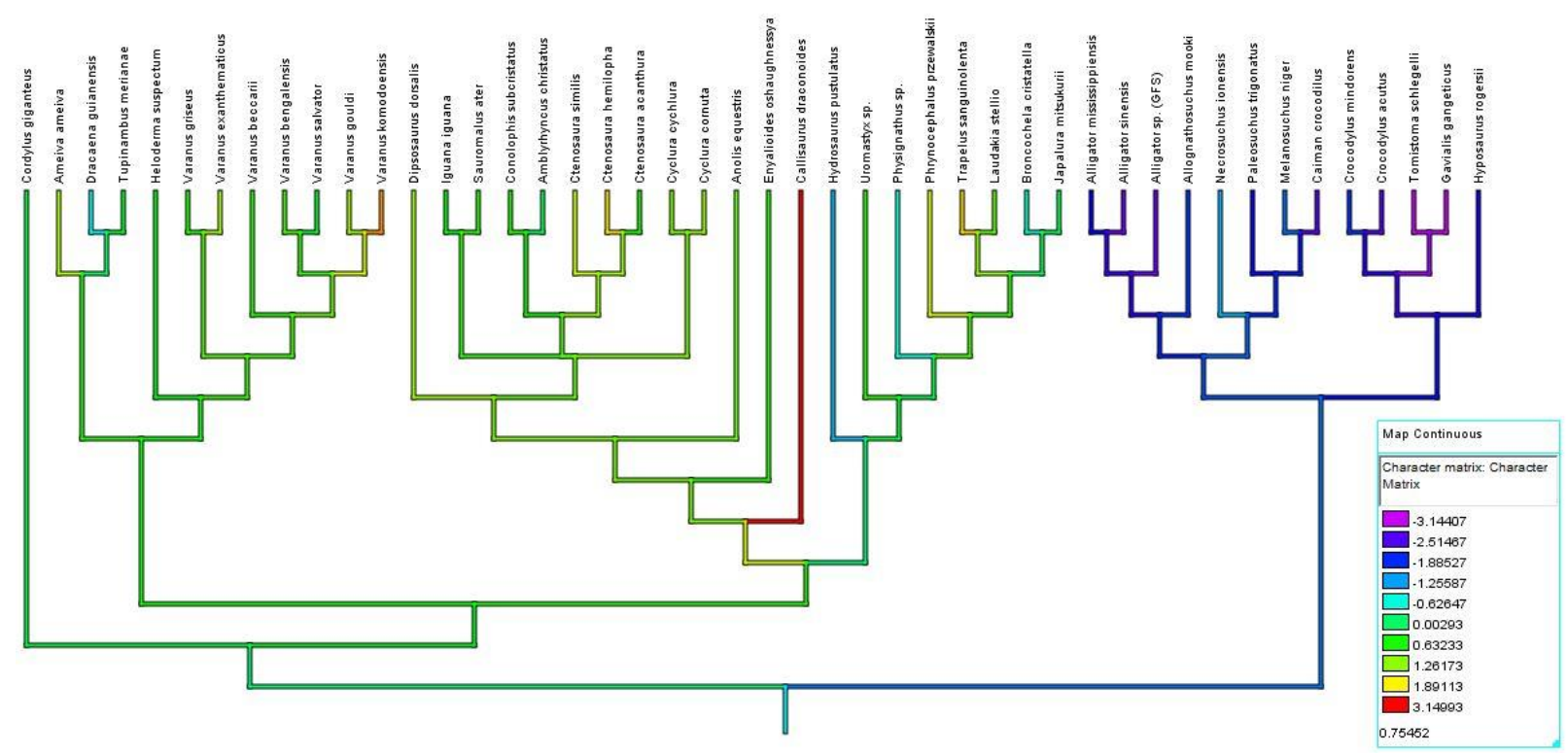

B)

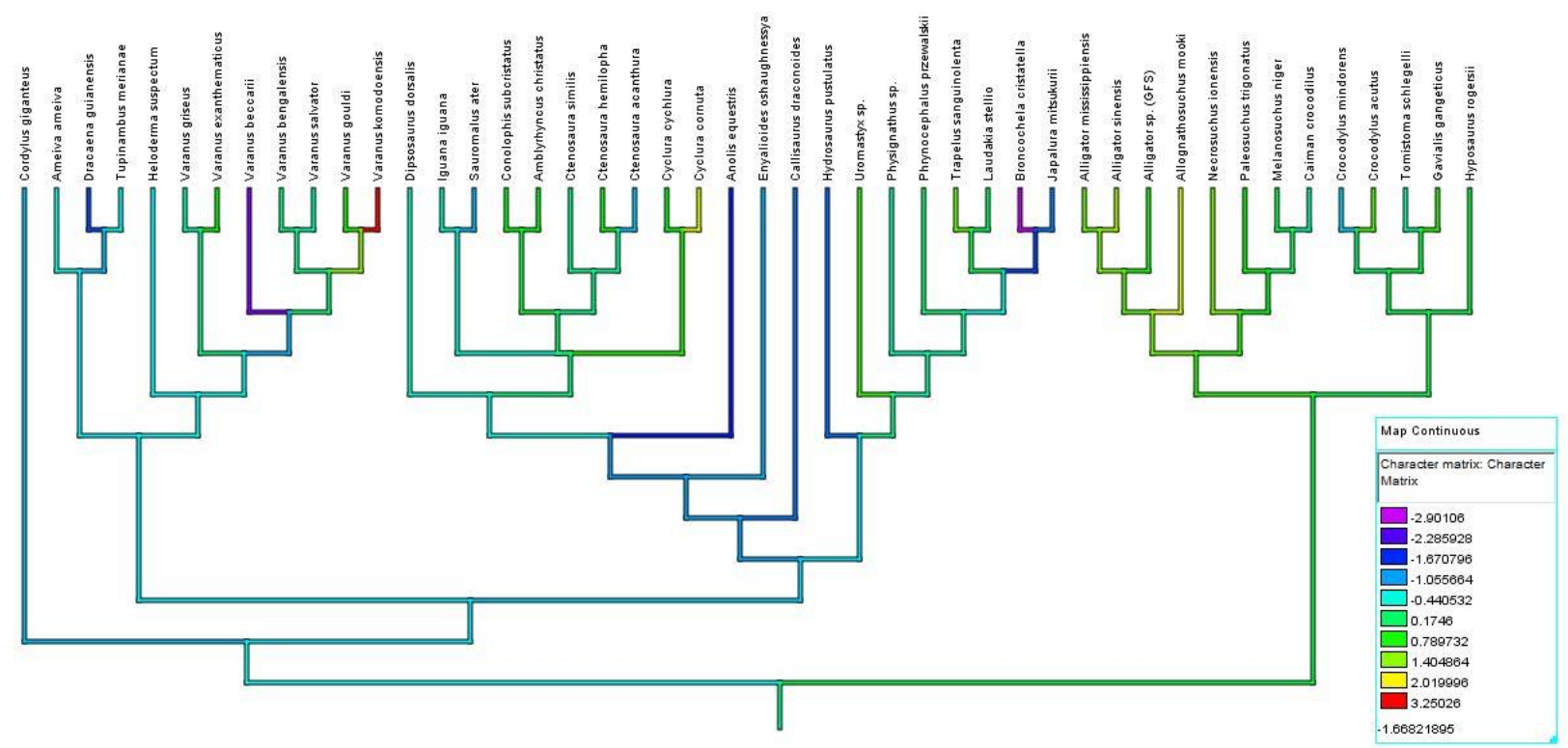

Figure 11: Composite phylogenetic tree of reptile species included within the study

Based on molecular and morphological analyses (Nesbitt, 2011; Bronzati et al., 2012; Pyron et al, 2013; Tucker et al., 2017). Branch colors represent discriminant function scores. a: Indices DF1 scores; $\boldsymbol{b}$ : Indices DF2 scores 


\section{Applications for Analyzing Locomotor Diversity of Extinct Reptiles}

Although several past studies have qualitatively examined the morphologies of extinct crocodylomorphs in order to determine their primary locomotor capabilities (Clark et al. 2004; Kellner et al. 2014; Blanco et al. 2015), this study has provided a unique quantitative assessment of morphological variation in extant reptile groups that can aid in more accurately interpreting the behavior and ecologies of fossil taxa. Fossil crocodylomorphs with morphologies that fall within the range of modern semi-aquatic taxa determined by these analyses were likely engaging in a very similar form of semi-aquatic behavior. There is no ideal modern analog for extinct crocodylomorph taxa, which are interpreted as engaging in higher degrees of terrestrial behavior as indicated by the presence of a more upright posture with legs oriented underneath the body versus the sprawled posture of extant terrestrial lepidosaurs. Despite this, the current ecomorphological framework would enable me to more easily determine if particular extinct species were utilizing a different form of locomotion, based on how similar they are to the morphospace ranges of modern groups.

The primary limitations of this study lie in a frequent lack of postcranial material for extinct specimens. Access to more complete specimens of extinct species and expansion into other groups of pseudosuchians, such as aetosaurs, would aid in inferring their locomotor modes and developing a more complete understanding of locomotor transitions in archosaurs through time.

All of the fossil crocodylomorphs included within this analysis classified as semi-aquatic and fall relatively closely within the range of modern semi-aquatic reptiles (Figure 8). Alligator sp. of the Gray Fossil Site, Allognathosuchus mooki, and Necrosuchus ionensis all group within 
Alligatoridae and Crocodylus affinis belongs to Crocodylidae (Simpson 1930; Brochu 2011;

Puértolas et al. 2011). These two families both span over 50 million years and still have living members today. My results indicate that even early members of these families, such as Allognathosuchus mooki and Necrosuchus ionensis from the Paleocene and Crocodylus affinis of the Eocene, were doing similar semi-aquatic behavior to more recent extinct taxa such as the Mio-Pliocene Alligator from the Gray Fossil Site and even modern crocodylian species.

Of the five fossil taxa that were classified, Hyposaurus rogersii (Family Dyrosauridae) displayed the highest value for $P(D \mid G)$ (Table 14), indicating it falls close to the centroid of the modern semi-aquatic group. Initial studies of Hyposaurus rogersii suggested that the species was largely marine, likely coming on land only to reproduce (Troxell 1925). More recent studies, however, have drawn attention to the well-developed limb morphology present in this species which potentially indicates terrestrial ancestry or a higher degree of terrestrial behavior than previously hypothesized (Denton Jr. et al., 1997). Specimens of this species have also been found in both marine and shallow subtidal environments. My results indicate that Hyposaurus rogersii displays distinct morphological similarities to extant semi-aquatic taxa, thus supporting more recent analyses that this species was engaging in a combination of both aquatic and terrestrial behavior similar to modern semi-aquatic reptiles.

While this study focused on examining extinct crocodylomorph taxa, these results have much broader potential applications. Phytosaurs, for example, display highly convergent morphologies with crocodylians and thus may have similarly identifiable aquatic or terrestrial adaptations. Examination of early archosaurs like Euparkeria could also help reveal the ancestral condition for that clade. Fossils of lepidosaurs may be examined as well to interpret 
their primary locomotor modes and gain a better understanding of the evolution of the wide diversity of locomotor behavior that we see within the clade today. Today's reptiles also bear distinct similarities to early amniotes; therefore, they may be able to act as a modern analog for early amniotes and reptiles, including well-known species like Seymouria, Hylonomus, and Petrolacosaurus, and also the early synapsids like pelycosaurs. Through the use of broader taxonomic sampling across groups such as chameleons, geckos, and phrynostomatids, we can span an even wider range of locomotor modes (fossorial, saltatorial, cursorial) and potentially identify shifts in predominant locomotor adaptations in these groups through time that could be the result of ecological shifts connected to the first transitions from life in water to life on land. 


\section{CHAPTER 6}

\section{CONCLUSIONS}

Through the use of simple linear morphometric analysis, I have determined that several features of the axial and appendicular skeleton reflect the locomotor modes of extant reptiles. Semi-aquatic species across both Crocodylia and Lepidosauria display convergent morphologies that reflect their similar locomotor adaptations despite significant phylogenetic separation between the groups. These methods may then be applied to extinct reptile groups to make more objective inferences of their past locomotor behavior based on quantitative analyses. Future expansion of this study into additional locomotor groups and reptile taxa may reveal other postcranial adaptations to these behaviors that will allow us to better understand the evolution of locomotion in this clade and examine the shifts in ecosystems through time that likely drove these changes. 


\section{REFERENCES}

Blanco, A., Fortuny, J., Alba, V., Luján, À. H., García-Marçà, J. A., \& Sellés, A. G. (2015). A new species of Allodaposuchus (Eusuchia, Crocodylia) from the Maastrichtian (Late Cretaceous) of Spain: phylogenetic and paleobiological implications. PeerJ; San Diego. https://peerj.com/articles/1171/

Brochu C. A. 2011. Phylogenetic relationships of Necrosuchus ionensis Simpson, 1937 and the early history of caimanines. Zoological Journal of the Linnean Society 163:S228-S256

Bronzati, M., Montefeltro, F., \& Langer, M. (2012). A species-level supertree of Crocodyliformes A species-level supertree of Crocodyliformes. Historical Biology, 24. https://doi.org/10.1080/08912963.2012.662680

Chen, M., \& Wilson, G. P. (2015). A multivariate approach to infer locomotor modes in Mesozoic mammals. Paleobiology, 41(2), 280-312. http://www.bioone.org/doi/10.1017/pab.2014.14

Clark, J. M., Xu, X., Forster, C. A., \& Wang, Y. (2004). A middle jurassic 'sphenosuchian' from china and the origin of the crocodylian skull. Nature, 430(7003), 1021-4. Retrieved from https://login.iris.etsu.edu:3443/login?url=https://search-proquestcom.iris.etsu.edu:3443/docview/204520663?accountid=10771

Da Silva, Filipe O., et al. "The Ecological Origins of Snakes as Revealed by Skull Evolution."Nature News, Nature Publishing Group, 25 Jan. 2018, www.nature.com/articles/s41467-01702788-3.

Denton Jr, Robert \& L. Dobie, James \& C. Parris, David. (1997). Chapter 13. The Marine Crocodilian Hyposaurus in North America. Journal of Vertebrate Paleontology. 14. 375397. 10.1016/B978-012155210-7/50020-X.

Fish FE. 1996. Transitions from drag-based to lift-based propulsion in mammalian swimming. Am Zool 36:628-641.

Gauthier, J. A., Nesbitt, S. J., Schachner, E. R., Bever, G. S., \& Joyce, W. G. (2011). The Bipedal Stem Crocodilian Poposaurus gracilis: Inferring Function in Fossils and Innovation in Archosaur Locomotion.Bulletin of the Peabody Museum of Natural History,52(1), 107126. https://doi.org/10.3374/014.052.0102

Gingerich PD. 2003. Land-to-sea transition in early whales: evolution of Eocene Archaeoceti (Cetacea) in relation to skeletal proportions and locomotion of living semiaquatic mammals. Paleobiology 29:429-454. 
Garland, T., \& Losos, J. (1994). Ecological morphology of locomotor performance in squamate reptiles. In Ecological morphology: integrative organismal biology. University of Chicago Press, Chicago, IL, USA (pp. 240-302).

Grenard, Steve, and Wanda Loutsenhizer. Handbook of Alligators and Crocodiles. Malabar, FL: Krieger Pub., 1991. Print.

Hua, S. (2003). Locomotion in marine mesosuchians (Crocodylia): The contribution of the "locomotion profiles". Neues Jahrbuch fur Geologie und Palaontologie - Abhandlungen. 227. 139-152.

Hua, S., \& Buffrenil, V. D. (1996). Bone histology as a clue in the interpretation of functional adaptations in the Thalattosuchia (Reptilia, Crocodylia). Journal of Vertebrate Paleontology, 16(4), 703-717. https://doi.org/10.1080/02724634.1996.10011359

Irmis, R. B.; Nesbitt, S. J.; Sues, H. -D. (2013). "Early Crocodylomorpha". Geological Society, London, Special Publications. 379: 275. doi:10.1144/SP379.24

Kellner, A. W., Pinheiro, A. E., \& Campos, D. A. (2014). A New Sebecid from the Paleogene of Brazil and the Crocodyliform Radiation after the K-Pg Boundary: e81386. PLoS One; San Francisco, 9(1).

http://journals.plos.org/plosone/article?id=10.1371/journal.pone.0081386

Klaczko, J., Sherratt, E., \& Setz, E. Z. F. (2016). Are Diet Preferences Associated to Skulls Shape Diversification in Xenodontine Snakes? PLoS One; San Francisco, 11(2), e0148375. http://journals.plos.org/plosone/article?id=10.1371/journal. pone.0148375

Liparini, A., \& Schultz, C. L. (2013). A reconstruction of the thigh musculature of the extinct pseudosuchian Prestosuchus chiniquensis from the Dinodontosaurus assemblage zone (Middle Triassic Epoch), Santa Maria 1 Sequence, southern Brazil. Special Publication Geological Society of London, 379(1), 441-468. http://sp.lyellcollection.org/content/early/2013/06/13/SP379.20

Losos JB. 2011. Convergence, adaptation, and constraint. Evolution 65:1827-1840.

Molnar, J. L., Pierce, S. E., Bhullar, B.-A. S., Turner, A. H., \& Hutchinson, J. R. (2015). Morphological and functional changes in the vertebral column with increasing aquatic adaptation in crocodylomorphs. Royal Society Open Science, 2(11). https://doi.org/10.1098/rsos.150439

Mosimann JE, James FC. 1979. New statistical methods for allometry with application to Florida red-winged blackbirds. Evolution 33:444-459.

Nemtzov SC (2005) Uromastyx lizards in Israel. NDF workshop case studies WG7, 5:22 
Nesbitt, S. J. (2011). The Early Evolution of Archosaurs: Relationships and the Origin of Major Clades. Bulletin of the American Museum of Natural History, 1-292.

https://doi.org/10.1206/352.1

O'Keefe FR, Carrano MT. 2005. Correlated trends in the evolution of the plesiosaur locomotor system. Paleobiology 31:656-675.

Pianka, E. R. (1969), Sympatry of Desert Lizards (Ctenotus) in Western Australia. Ecology, 50: 1012-1030. doi:10.2307/1936893

Pounds, J., Jackson, J., \& Shively, S. (1983). Allometric Growth of the Hind Limbs of Some Terrestrial Iguanid Lizards. The American Midland Naturalist, 110(1), 201-207. doi:10.2307/2425226

Puértolas E., Canudo J. I., and Cruzado-Caballero P. 2011. A new crocodylian from the late Maastrichtian of Spain: Implications for the initial radiation of crocodyloids. PLoS One 6(6):e20011:1-12

Pyron, R. A., Burbrink, F. T., \& Wiens, J. J. (2013). A phylogeny and revised classification of Squamata, including 4161 species of lizards and snakes. BMC Evolutionary Biology; London, 13, 93. https://bmcevolbiol.biomedcentral.com/track/pdf/10.1186/1471-214813-93

Romer, Alfred Sherwood. Osteology of the Reptiles. Malabar, FL: Krieger, 1997. Print.

Rose, Jacob A. \& Moore Crisp, Lexi \& Russell, Anthony \& Butcher, Michael. (2014). Functional osteology of the forelimb digging apparatus of badgers. Journal of Mammalogy. 95. 543558. 10.1644/13-MAMM-A-174.

Samuels, J. X., \& Van Valkenburgh, B. (2008). Skeletal indicators of locomotor adaptations in living and extinct rodents. Journal of Morphology, 269(11), 1387-1411. https://www.ncbi.nlm.nih.gov/pubmed/18777567

Samuels, J. X., Meachen, J. A., \& Sakai, S. A. (2013). Postcranial morphology and the locomotor habits of living and extinct carnivorans. Journal of Morphology (1931), 274(2), 121-146. https://onlinelibrary.wiley.com/doi/full/10.1002/jmor.20077

Schachner, E. R. (2010).Anatomical reconstructions of respiratory morphology and hindlimb musculature in Poposaurus gracilis(Archosauria: Poposauroidea) and related dinosauriformes (Ph.D.). University of Pennsylvania, United States -- Pennsylvania. Retrieved from http://search.proquest.com.iris.etsu.edu:2048/docview/758924912/abstract/F12B40F3 CBFA40A6PQ/2 
Simpson G. G. 1930. Allognathosuchus mooki, a new crocodile from the Puerco Formation. American Museum Novitates 445:1-16

Stayton, C. Tristan. "Testing Hypotheses of Convergence with Multivariate Data: Morphological and Functional Convergence among Herbivorous Lizards." Evolution; International Journal of Organic Evolution 60.4 (2006): 824-841. Print.

Stein B. 1988. Morphology and allometry in several genera of semiaquatic rodents (Ondatra. Nectomys, and Oryzomys). J Mammal 69:500-511.

Stein, M. D., Yates, A., Hand, S. J., \& Archer, M. (2017). Variation in the pelvic and pectoral girdles of australian Oligo-Miocene mekosuchine crocodiles with implications for locomotion and habitus. PeerJ, http://dx.doi.org.iris.etsu.edu:2048/10.7717/peerj.3501 Retrieved from https://login.iris.etsu.edu:3443/login?url=https://search-proquestcom.iris.etsu.edu:3443/docview/1953014015 ?accountid=10771

Toro, E., A. Herrel, and D. Irschick. 2004. The Evolution of Jumping Performance in Caribbean Anolis Lizards: Solutions to Biomechanical Trade-Offs. The American Naturalist.

Troxell E. L. 1925. Hyposaurus, a marine crocodilian. American Journal of Science 9:489-514

Tucker, D. B., Hedges, S. B., Colli, G. R., Pyron, R. A., \& Sites, J. W. (2017). Genomic timetree and historical biogeography of Caribbean island ameiva lizards (Pholidoscelis:

Teiidae). Ecology and Evolution, 7(17), 7080-7090. https://doi.org/10.1002/ece3.3157

Tulli, Michele et al. "Morphological Variation of the Forelimb and Claw in Neotropical Sigmodontine Rodents (Rodentia: Cricetidae)." Journal of Mammalian Evolution 23 (2015): 81-91.

Vanhooydonck, B., and R. van Damme. 1999. Evolutionary relationships between body shape and habitat use in lacertid lizards. Evolutionary Ecology

Van Valkenburgh B. 1987. Skeletal indicators of locomotor behavior in living and extinct carnivores. J Vert Paleontol 7:162-182.

Verwaijen, D., and R. van Damme. 2007. Does foraging mode mould morphology in lacertid lizards? Journal of Evolutionary Biology.

Vitt, L. J., \& Caldwell, J. P. (2013). Herpetology: An Introductory Biology of Amphibians and Reptiles. Academic Press.

Wainwright, Peter C. "Functional Versus Morphological Diversity in Macroevolution." Annual Review of Ecology, Evolution, and Systematics, vol. 38, no. 1, 2007, pp. 381-401., doi:10.1146/annurev.ecolsys.38.091206.095706. 
Webb PW, Blake RW. 1985. Swimming. In: Hildebrand M, Bramble DM, Liem KF, Wake DB, editors. Functional vertebrate morphology. Cambridge, MA: Harvard University Press. pp. 111-128. 
VITA

\section{LAURA ANN ROONEY}

Education:

Professional Experience:

Publications:

Honors and Awards:
B.A. Anthropology, Macaulay Honors College at CUNY Hunter College, New York, NY 2015

M.S. Geosciences with Concentration in Paleontology, East Tennessee State University, Johnson City, TN, 2018

Student Research Associate, Assistant Crew Chief, and Educator, Bighorn Basin Paleontological Institute, 2013-present

Intern, Academy of Natural Sciences of Drexel University, Philadelphia, Pennsylvania, 2015-2016

Intern, New Jersey State Museum, Trenton, New Jersey, 2016

Volunteer, Gray Fossil Site and Museum, Gray, Tennessee, 2017-present

Teaching Assistant, East Tennessee State University, Johnson City, TN, 2016-present

Lab Coordinator, East Tennessee State University, Johnson City, TN, 2017-present

Rooney, L. A., Samuels, J.X., 2017. Postcranial morphology and the locomotor adaptations of extant and extinct crocodylomorphs and lepidosaurs. Presented at 2017 Society of Vertebrate Paleontology meeting, Calgary, Canada

Malinowski, B. L., Rooney, L. A., Schein, J. P., Poole, J. C., A New Partial Skeleton of Leptoceratops gracilis from the Lance Formation of Wyoming, U.S.A. Presented at 2016 Society of Vertebrate Paleontology meeting, Salt Lake City, Utah

University Scholar.

Four-year merit scholarship, Macaulay Honors College.

Dorothy Keur Memorial Scholarship.

Anthropology Majors with High GPA, Hunter College. Dean's List.

3.50 GPA or higher, 7 semesters, Hunter College. 